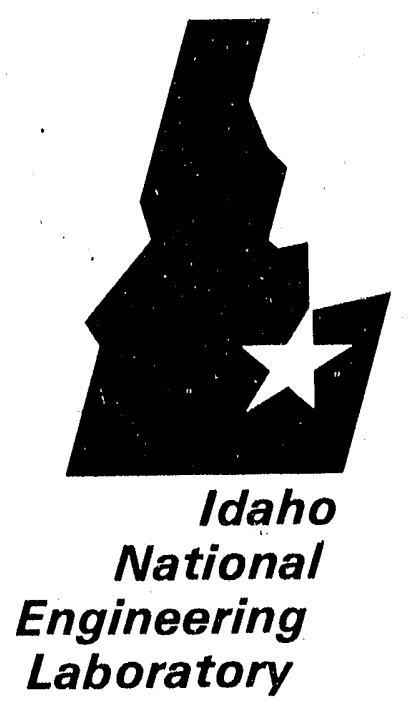

\author{
Managed \\ by the U.S. \\ Department \\ of Energy
}

EGG-NE-10078

January 1992

\section{APR2? 1992}

INFORMAL REPORT

Statistically Based Uncertainty Analysis for Ranking of Component Importance in the Thermal-Hydraulic Safety Analysis of the Advanced Neutron Source Reactor

G. E. Wilson

\title{
5 EGrGidaho
}

Work performed under

DOE Contract

No. DE-AC07-761D01570 


\section{STATISTICALLY BASED UNCERTAINTY ANALYSIS FOR RANKING OF COMPONENT IMPORTANCE IN THE THERMAL-HYDRAULIC SAFETY ANALYSIS OF THE ADVANCED NEUTRON SOURCE REACTOR}

Informal Report

Gary E. Wilson

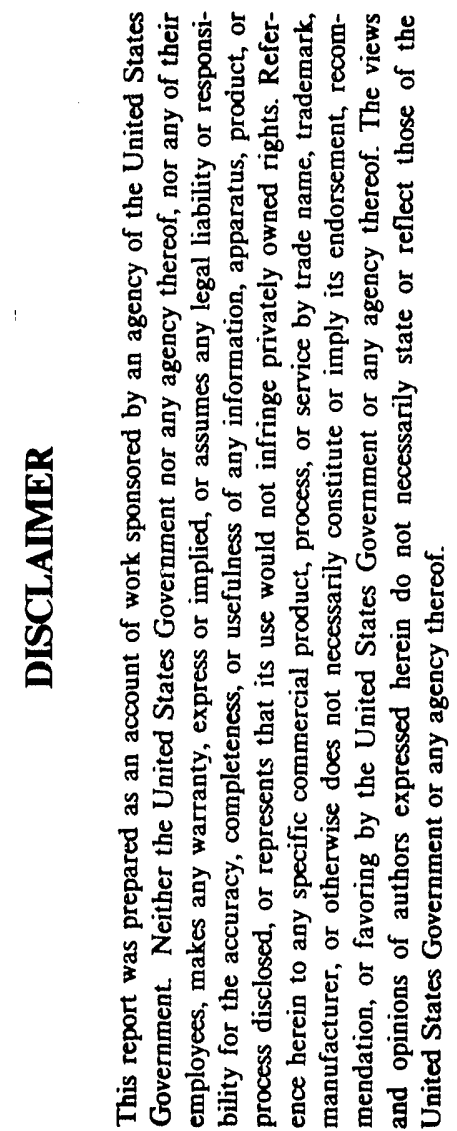

Idaho National Engineering Laboratory EG\&G Idaho, Inc. PO Box 1625 Idaho Falls, ID 83415

Prepared for the US Department of Energy Idaho Operations Office Under DOE Contract No. DE-AC07-76IDO1570 


\begin{abstract}
The Analytic Hierarchy Process (AHP) has been used to help determine the importance of components and phenomena in thermal-hydraulic safety analyses of nuclear reactors. The AHP results are based, in part on expert opinion. Therefore, it is prudent to evaluate the uncertainty of the AHP ranks of importance. Prior applications have addressed uncertainty with experimental data comparisons and bounding sensitivity calculations. These methods work well when a sufficient experimental data base exists to justify the comparisons. However, in the case of limited or no experimental data the size of the uncertainty is normally made conservatively large. Accordingly, the author has taken another approach, that of performing a statistically based uncertainty analysis.

The new work is based on prior evaluations of the importance of components and phenomena in the thermal-hydraulic safety analysis of the Advanced Neutron Source Reactor (ANSR), a new facility now in the design phase. The uncertainty during large break loss of coolant, and decay heat removal scenarios is estimated by assigning a probability distribution function (pdf) to the potential error in the initial expert estimates of pair-wise importance between the components. Using a Monte Carlo sampling technique, the error pdfs are propagated through the AHP software solutions to determine a pdf of uncertainty in the system wide importance of each component.

To enhance the generality of the results, study of one other problem having a different number of elements is reported, as are the effects of a larger assumed pdf error in the expert ranks. Validation of the Monte Carlo sample size and repeatability are also documented.
\end{abstract}




\section{EXECUTIVE SUMMARY}

The Analytic Hierarchy Process (AHP) has been used to help determine the importance of components and phenomena in thermal-hydraulic safety analyses of nuclear reactors. The AHP results are based, in part on expert opinion. Therefore, it is prudent to evaluate the uncertainty of the AHP ranks of importance. Typically, prior applications have addressed this topic by:

a) Comparing the AHP results with experimental data, and

b) Performing limited, but bounding sensitivity analyses.

These methods work well when a sufficient experimental data base exists to justify the comparisons. However, in the case of limited or no experimental data the uncertainty is normally made conservatively large. Accordingly, the author has taken another approach, that of performing a statistically based uncertainty analysis.

The new work is based on evaluations of the importance of components and phenomena in the thermal-hydraulic safety analysis of the Advanced Neutron Source Reactor (ANSR), a new facility now in the design phase. The uncertainty in the importance of the components in the ANSR to safety analysis of the system behavior during large break loss of coolant, and decay heat removal scenarios is estimated by assigning a probability distribution function (pdf) to the potential error in the initial expert estimates of pair-wise importance between the components. Using a Monte Carlo sampling technique, the error pdfs are propagated through the AHP software solutions to determine a pdf of uncertainty in the system wide importance of each component.

From the results reported herein it is concluded that, when properly applied, the AHP is a robust methodology to determine the relative importance of components and phenomena in safety analyses of nuclear reactors. Specificallv for the ANSR, the likelihood of a change of one in the originally determined component importance levels (high to moderate, moderate to high or low, or low to moderate) is less than $13 \%$, on the average. There is zero probability of a change of two levels (high to low or low to high).

While the ANSR Phenomena Identification and Ranking Process (PIRP) results are the primary focus of this work, the author believes the new uncertainty quantification approach is more widely applicable (i.e., to similar PIRP analyses). Therefore, in addition to the study of the ANSR ranking, the uncertainty analysis also includes study of one other problem having a different number of elements. The 
results from the analysis of Saaty problem 103, a six element matrix (45\% smaller than the ANSR matrices), indicate the AHP remains robust for problems having fewer elements. However, the uncertainty increases as the number of elements decrease. It is concluded that problems having fewer than six elements should specifically include uncertainty analyses in their evaluations. At a minimum, bounding sensitivity studies should be conducted. Statistically based analyses, similar to that reported herein would be even better. 


\section{CONTENTS}

ABSTRACT .ii

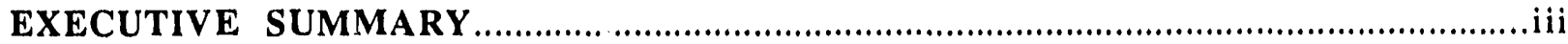

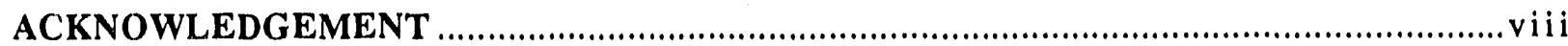

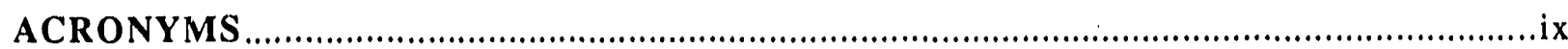

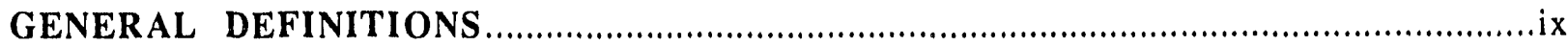

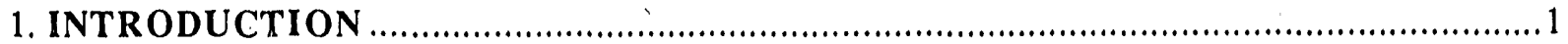

2. ANSR BACKGROUND AND BASIS FOR THE UNCERTAINTY ANALYSIS ........2

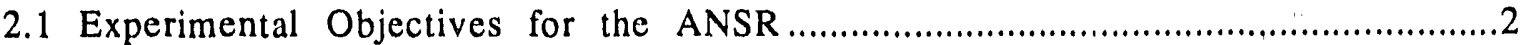

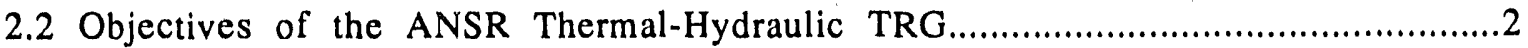

2.3 Summary of PIRP Results for LBLOCA and Decay Heat Transients....................2

3. STATISTICALLY BASED UNCERTAINTY ANALYSIS APPROACH ..................4

3.1 Background for New Uncertainty Quantification Approach...........................4

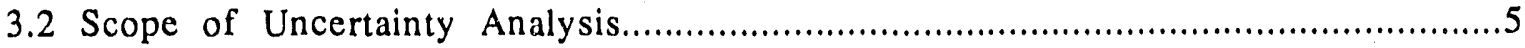

3.3 Statistically Based Uncertainty Quantification Approach...........................6

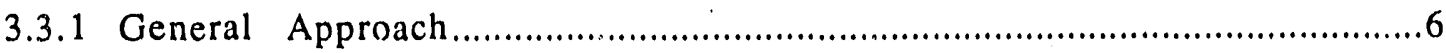

3.3.2 Assumed Error in Original Pair-Wise Component Ranks.......................8

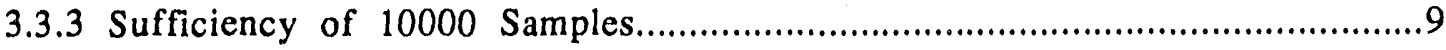

3.3.4 Sufficiency of Saaty's Approximate Solution.......................................10

4. RESULTING PDFS FOR THE ORIGINAL BE COMPONENT RANKS...................11

4.1 Uncertainty in the Original BE Component Importance Ranks....................11

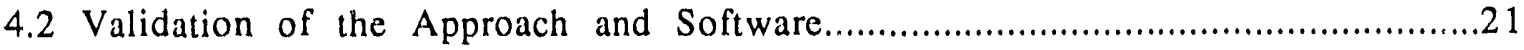

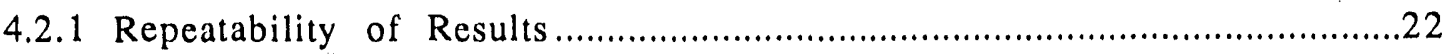

4.2.2 Acceptable Convergence in ANSR Analysis at 10000 Monte Carlo Samples..................................................................................23

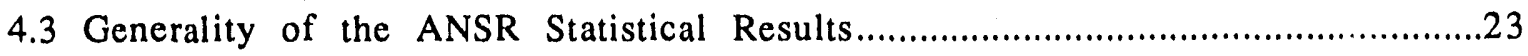

5. SUMMARY OF RESULTS AND CONCLUSIONS...............................................33

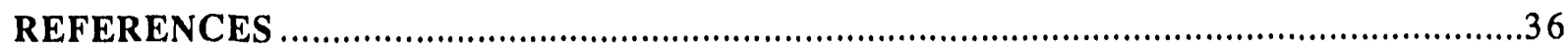

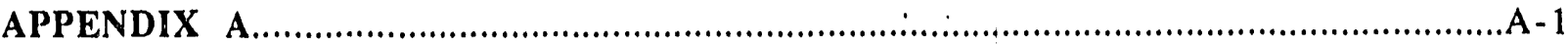

APPENDIX B 
CONTENTS (continued)

TABLES

1. Summary of component importance from AHP analysis by the TRG......................3

2. Uncertainty in ANSR LBLOCA original component importance based on the BE pdf for the potential error in the original expert pair-wise ranks - Original run.

3. Uncertainty in ANSR LBLOCA original component importance based on the $B E$ pdf for the potential error in the original expert pair-wise ranks - Repeat run.

4. Uncertainty in ANSR LBLOCA original component importance based on the sensitivity pdf for the potential error in the original expert pair-wise ranks - Original run.

5. Uncertainty in ANSR LBLOCA original component importance based on the sensitivity $\mathrm{pdf}$ for the potential error in the original expert pair-wise ranks - Repeat run......

6. Uncertainty in ANSR decay heat removal original component importance based on the $\mathrm{BE}$ pdf for the potential error in the original expert pair-wise ranks - Original run.

7. Uncertainty in ANSR decay heat removal original component importance based on the $\mathrm{BE}$ pdf for the potential error in the original expert pair-wise ranks - Repeat run.

8. Uncertainty in ANSR decay heat removal original component importance based on the sensitivity pdf for the potential error in the original expert pair-wise ranks - Original run.

9. Uncertainty in ANSR decay heat removal original component importance based on the sensitivity pdf for the potential error in the original expert pair-wise ranks - Repeat run.

10. Uncertainty in Saaty problem 103 original component importance based on the $B E$ pdf for the potential error in the original expert pair-wise ranks - Original run.

11. Uncertainty in Saaty problem 103 original component importance based on the $\mathrm{BE}$ pdf for the potential error in the original expert pair-wise ranks - Repeat run 
CONTENTS (continued)

\section{TABLES (continued)}

12. Uncertainty in Saaty problem 103 original component importance based on the sensitivity pdf for the potential error in the original expert pair-wise ranks - Original run.

13. Uncertainty in Saaty problem 103 original component importance based on the sensitivity pdf for the potential error in the original expert pair-wise ranks - Repeat run

\section{FIGURES}

1. Illustration of Monte Carlo approach to determining the uncertainty in the importance of the components to the safety analysis....

2. Assumed pdf for potential errors in the original best estimate component pair-wise ranks.

3. Sensitivity pdf for potential errors in the original best estimate component pair-wise ranks.

4. Summary of uncertainty in ANSR original importance levels based on the BE pdf for potential error in experts original pair-wise ranks.

5. Summary of uncertainty in ANSR original importance levels based on the sensitivity pdf for potential error in experts original pair-wise ranks.............20

6. Comparison of ANSR BE original and repeat run importance levels....................22

7. Comparison of ANSR sensitivity original and repeat run importance levels.......22

8. Illustration of the convergence of the BE ANSR uncertainty runs.....................24

9. Illustration of the convergence of the sensitivity ANSR uncertainty runs........25

10. Comparison of ANSR and Saaty problem 103 BE importance levels.......................30

11. Comparison of ANSR and Saaty problem 103 sensitivity importance levels........31 


\section{ACKNOWLEDGEMENTS}

The study reperted here is based on the work of a Technical Review Group setup by Oak Ridge National Laboratory to evaluate the importance of components and phenomena in the thermal-hydraulic safety analysis of the Advanced Neutron Source Reactor. The Technical Review Group members were: Dr. Lap Cheng (BNL), Dr. Richard Dimenna (SRL), Dr. Peter Griffith (MIT), Mr. Art Ruggles (ORNL Chairman), and Mr. Gary E. Wilson (INEL).

In addition to providing the basis for this study, the Technical Review Group reviewed drafts of this report and provided valuable comments. The author gratefully acknowledges this support. 


\section{ACRONYMS}

AHP Analytic hicrarchy process

ANSR Advanced neutron source reactor

BE Best estimate

BNL Brookhaven National Laboratory

CSAU Code scaling, applicability and uncertainty

DEGB Double ended guillotine break

INEL Idaho National Engineering Laboratory

LBLOCA Large break loss of coolant accident

MIT Massachusetts Institute of Technology

ORNL Oak Ridge National Laboratory

PC Personal computer

PIRP Phenomena identification and ranking process

PIRT Phenomena identification and ranking table

SRL Savannah River Laboratory

\section{GENERAL DEFINITIONS}

Pair-wise rank - Compar:son of attribute (a) to attribute (b) with respect to their relative importance to the specified criteria. Pair-wise comparisons are the most basic evaluations used in the AHP (see Appendix A for additional detail).

Ordered rank - Measure of the relative importance of attribute (a) to all other attributes (at the same hierarchical level) with respect to the specified criteria at that level (see Appendix A for additional detail). Ordered ranks are determined from matrix solutions of the pair-wise ranks associated with the subject attributes.

Qperational, investment or safety criteria - Criteria used to judge the relative importance (pair-wise ranks) of attribute (a) to attribute (b) to cost effective operation, or uptimized investment cost, or public safety associated with nuclear reactors.

Potential error pdf - Probability density function for the possible error in expert pair-wise ranking.

Uncertainty $\mathrm{pdf}$ - Probability density function of the uncertainty in ordered ranks as determined by the matrix solutions of the pair-wise ranks using the potential error pdf. That is, propagation of the potential error pdf through the AHP to define the uncertainty in the resulting ordered ranks. 


\section{STATISTICALLY BASED UNCERTAINTY ANALYSIS FOR RANKING OF COMPONENT IMPORTANCE IN THE THERMAL-HYDRAULIC SAFETY ANALYSIS OF THE ADVANCED NEUTRON SOURCE REACTOR}

\section{INTRODUCTION}

The Analytic Hierarchy Process (AHP), originally developed by T. L. Saaty (Appendix A), has been adapted and applied to numerous studies $[1,2,3,4]$ related to thermal-hydraulic safety analyses of nuclear reactors. Because of the partially subjective nature of AHP, a common peer-review response is to question the uncertainty in the ranking of phenomena importance to satisfying the primary safety criteria. Typically, the prior applications $[1,2,3]$ have addressed this topic by:

a) Comparing the AHP results with experimental data, and

b) Performing limited, but bounding sensitivity analyses.

These methods work well when a sufficient experimental data base exists to justify the comparisons. However, in the case of limited or no experimental data the validity of the uncertainty quantification is less certain. Accordingly, the author has taken another approach, that of performing a statistically based uncertainty analysis.

The work reported here is based on evaluations of the importance of components and phenomena in the thermal-hydraulic safety analysis of the Advanced Neutron Source Reactor (ANSR), as determined by a Technical Review Group (TRG) setup by Oak Ridge National Laboratory (ORNL) to address that topic. The ANSR Phenomena Identification and Ranking Process (PIRP) evaluations are an appropriate basis for application of the new uncertainty analysis approach because the ANSR is a new experimental facility just now being designed (i.e., there is only a limited data base related to the potential performance of the reactor).

While the ANSR PIRP results are the primary focus of this work, the author believes the new uncertainty quantification approach is more widely applicable (i.e., to similar PIRP analyses). Therefore, in addition to the study of the ANSR ranking, the uncertainty analysis also includes study of one other problem having a different number of elements. This problem is one employed to validate the AHP software[5] used to perform the ANSR PIRP analysis.

This report is organized to describe the ANSR PIRP basis in Section 2, the statistically based uncertainty analysis approach in Section 3 , significant results in Section. 4, and conclusions in Section 5. A listing of referenced documents follows 
Section 5. Additional information related to various topics is provided in the appendices.

\section{ANSR BACKGROUND AND BASIS FOR THE UNCERTAINTY ANALYSIS}

Information relating to the basis for the uncertainty analysis of this report is described in this section. The objectives for constructing the ANSR and for the PIRP analysis are given in Sections 2.1 and 2.2 , respectively. The Best Estimate (BE) component importance developed by the TRG is summarized in Section 2.3.

\subsection{Experimental Objectives for the ANSR}

The ANSR is a new research facility planned to meet the need for an intense steady-state source of neutrons, associated instruments, and experimental space. The facility will provide intense beams of cold, thermal and hot neutrons for materials science studies and basic nuclear physics experiments. A typical example might be testing materials for possible use in fusion reactors which requires a fast neutron spectrum, but where the copious production of transuranium isotopes needs a high epithermal flux $[6,7]$.

\subsection{Objectives of the ANSR Thermal-Hydraulic TRG}

The ANSR program at ORNL has progressed to the conceptual design phase. That is, the basic plant design is established and the continuing work will be primarily associated with refinements to the basic design. In support of optimizing the final plant design for operations and safety, ORNL has decided to use the PIRP from the Code Scaling, Applicability and Uncertainty (CSAU) methodology[1] to help establish requirements for experimentation and code development. In accordance with past successful practice in the use of the PRIP, the TRG was established to help ORNL personnel apply the methodology.

\subsection{Summary of PIRP Results for LBLOCA and Decay Heat Transients}

The BE evaluations of component importance to safety analysis of LBLOCA and decay heat scerarios are summarized in Table 1 . The importance levels given in Table 1 are on a scale of 1 to 9, where the general interpretation is that 1 to 3 equals low importance, 4 to 6 equals moderate importance, and 7 to 9 equals high importance, with respect to the following safety criteria. 
The "safety criterion" by which the LBLOCA components were judged is incipient fuel and/or control red damage. This criterion is based on ORNL's intent to design the reactor to prohibit such damage for all plausible accident scenarios.

For the decay heat removal scenario the "safety criterion" was the enset of significant voids. This criterion is based on ORNL's intent to design the reactor so that decay heat removal is accomplished by single phase natural circulation.

Table 1. Summary of component importance from AHP analysis by the TRG.

\begin{tabular}{|c|c|c|c|}
\hline \multicolumn{2}{|l|}{ LBLOCA } & \multicolumn{2}{|c|}{ Decay Heat Removal } \\
\hline Component & Importarce & Component & Importance \\
\hline Fuel assembly & 9 & Fuel assembly & 9 \\
\hline Break & 9 & Primary heat exchanger & 7 \\
\hline Control rods & 6 & Cooling tower basin & 5 \\
\hline Accumulator & 6 & Pumps & 5 \\
\hline Targets & 3 & Hot leg & 3 \\
\hline Pumps & 3 & Cold leg & 3 \\
\hline $\begin{array}{l}\text { Core pressure boundary } \\
\text { tube (CPBT) }\end{array}$ & 3 & $\begin{array}{l}\text { Pool (flooded volume } \\
\text { surrounding hot \& cold } \\
\text { legs, pumps, Hxs, etc. }\end{array}$ & 3 \\
\hline Bypass & 2 & $\begin{array}{l}\text { Emergency heat } \\
\text { exchanger }\end{array}$ & 2 \\
\hline Cold leg & 2 & Control rods & 2 \\
\hline Hot leg & 2 & CPBT & 2 \\
\hline Primary heat exchanger & 2 & $\begin{array}{l}\text { Secondary system hot \& } \\
\text { cold legs }\end{array}$ & 2 \\
\hline Pressurization system & 1 & Bypass & 2 \\
\hline $\begin{array}{l}\text { Emergency heal } \\
\text { exchanger }\end{array}$ & 1 & Reflector tank & 1 \\
\hline Secondary systems & 1 & Targets & 1 \\
\hline & & Pressurization system & 1 \\
\hline & & Break & 1 \\
\hline
\end{tabular}




\section{STATISTICALLY BASED UNCERTAINTY ANALYSIS APPROACH}

The new method of estimating the uncertainty in the importance of components and/or phenomena to safety analysis is described in this section. The background and motivation for the current study is given in Section 3.1. The scope of the uncertainty analysis is described in Section 3.2. The approach is described in Section 3.3 .

\subsection{Background for New Uncertainty Quantification Approach}

The $\operatorname{AHP}[8,9,10,11,12,13,14]$ allows a systematic, logical approach to reducing complex issues into manageable pieces (Appendix A). The decision maker can then sort through the variables and determine to what degree a particular variable should influence the final decision (goa!) The power of the AHP as a decision making tool comes from the fact that it reduces the problem to many pair-wise decisions. Only two items need be compared against one another, a much simpler task than comparing an item to all the others simultaneously. By comparing appropriate pairs in a priority matrix, each item will have been compared with every other item. Matrix algebra can then opcrate on this priority matrix to rank the items according to their importance toward achieving the goal.

The structured approach of the AHP is a significant aid in organizing a problem and in providing a common basis for communication hetween experts. However, even though the experts are generally guided toward a consensus as to the relative importance of the elements at the top level, the expert opinions remain somewhat subjective because the basic decisions (i.e., the lowest most pair-wise ranks) reflect the epiniens of the experts. Therefore, it is necessary that the experts demonstrate the validity of their basic decisions. Typically, this has been previously done in two steps:

a) The lowest level pair-wise ranks are related to experimental data to the maximum extent possible. It is paramount this be done both before and after application of the AHP to obtain the final top level ranks. That is, the AHP results should be carefully reviewed, and in any case where these results do not fully reflect a common consensus, additional effort is made to tie the initial pair-wise ranks to specific evidence showing their validity. In any case where the evidence may be judged to be weak, then higher levels of importance may be assumed until better knowledge is available. 
b) Sensitivity studies are made where the weakest initial pair-wise ranks are assigned higher levels of importance. Commonly, these studies are limited to acceptable efforts in terms of resource allocation by combining the several weakest pair-wise ranks in a fashion producing bounding results.

It is the second step above that is addressed in a new way in this report. That is, every pair-wise rank in a matrix is assigned a common statistically based uncertainty (i.e., a probability distribution function ( $p d f$ ) for potential error). Then using a Monte Carlo sampling approach, the pdf of the uncertainty in the relative importance of the top level elements in the matrix, as deternined by the AHP, is generated.

\subsection{Scope of Uncertainty Analysis}

The ultimate goal of the TRG is to determine the importance of phenomena to the safety criteria on a system wide basis. The importance of the phenomena, in the system sense, is related to the importance of the phenomena within any component, combined with the importance of that component to the total reactor behavior. This structure is evident in the two-tiered hierarchy used by the TRG to apply the AHP (See Figure A3 in Appendix A for example). In this structure, the components are pair-wise ranked at the first level, with the phenomena pair-wise ranked for their importance in each component at the second level. The AHP software then calculates the relative importance of the phenomena within each component, the relative importance of each component to the system behavior, and finally the importance of the phenomena to system behavior by weighting their importance in each component by the component's importance.

Because of the structure just described, a fully complete uncertainty analysis would be conducted using the original two-tiered AHP structure. However, it is readily apparent that such an approach would involve millions of calculations not particularly amenable to timely solution on a PC, nor considered necessary to the current objective. Prior application of the AHP[3] has demonstrated that in a similar two-tiered analysis the system level importance of a phenomenon will not exceed its component importance by more than one unit (on a scale of 1 to 9), regardless of how important the phenomenon is within the component. Thus it was judged that limiting the current work to just the evaluation of the component importance was sufficient to the objective. 


\subsection{Statistically Based Uncertainty Quantification Approach.}

\subsubsection{General Approach}

The new approach is conceptually illustrated in Figure 1. A description of the major steps in the apprach follows.

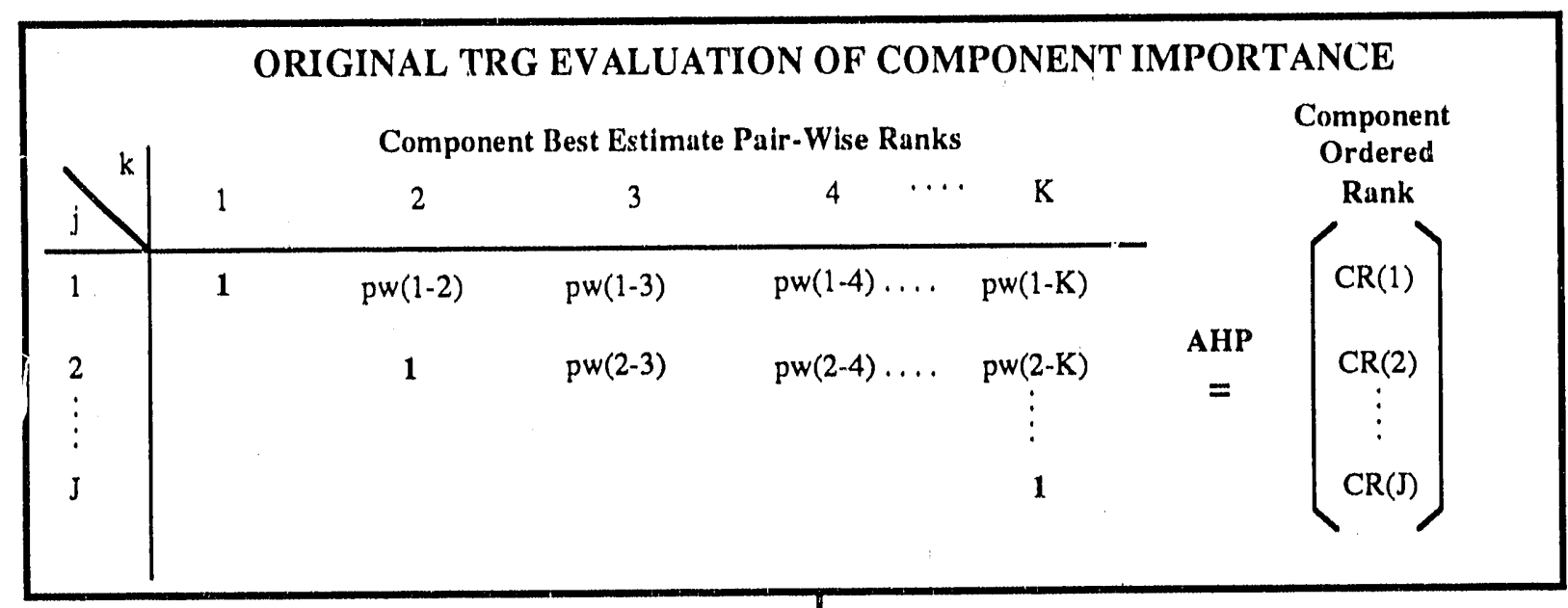

Calculate the pdfs for the uncertainty in the original compunent ordered ranks.
For $\mathrm{j}=1$ through $\mathrm{J}-1$ and $\mathrm{k}=(\mathrm{j}+1)$ through $\mathrm{K}$, randomly select the potential error in each pw(j,k) using the assumed pdf for the original pair-wise ranks. Calculate the new pair-wise ranks = best estimate $\mathrm{pw}(\mathrm{j}, \mathrm{k})+\operatorname{error}(\mathrm{j}, \mathrm{k})$
Using the AHP calculate the new importance of each component ; $\mathrm{CR}(1)$ thru $\mathrm{CR}(\mathrm{J})$. Then calculate Change $(j)=C R(j)$, original $-\mathrm{CR}(\mathrm{j})$, new

Figure 1. Illustration of Monte Carlo approach to determining the uncertainty in the importance of the components to the safety analysis. 
1) As shown in the upper part of Figure 1, the basis of the analysis is the original BE pair-wise component ranks assigned by the TRG $(\mathrm{pw}(\mathrm{j}-\mathrm{k})$ ), followed by application of the AHP software to determine the component importance to the system behavior $(\mathrm{CR}(\mathrm{j}))$.

2) For each Monte Carlo sample, and using an assumed pdf for the potential error in the original BE pair-wise ranks (Section 3.3.2), a randomly selected error is generated for each original pair-wise rank (for $j=1$ to $\mathrm{J}-1$ and $k=(j+1$ ) to $K$ ). Only the upper diagonal of the matrix is so treated because the ranks in the lower diagonal are the inverse of the upper ranks. In addition, no new pairwise rank is allowed to exceed the end points of the original ranking scale. For example, assume the pair-wise ranking scale is 1 to 5 , and that an original pairwise rank plus the randomly selected error is greater than 5 . In this case the new pair-wise rank would be assigned the maximum value 5 .

3) Calculate the new component importance ranks with the above determined pair-wise ranks, followed by calculation of the algebraic difference in each of the new ranks from the original best estimate ranks. These differences are "binned" for each component. That is, for a difference of $x$, bin $x$ is incriminated by 1 , where $-8 \leq x \leq 8$ because the AHP software provides the component importance ranks in a relative scale of 1 to 9.

4 ) Repeat Steps 2 and 3 until a sufficient number of samples have been taken. A sufficiency test will be described subsequently.

5) Calculate the pdf in the original BE component importance ranks. The pdf is a function of the value in each bin $x$ divided by the number of Monte Carlo samples.

Three key assumptions are imbedded in the analysis scheme illustrated in Figure 1:

a) A realistic pdf can be defined for the potential error in the original pair-wise ranks assigned by the experts.

b) 10,000 Monte Carlo samples are sufficient to achieve convergence in the pdfs for the uncertainty in the AHP derived orders of importance of the components.

c) Saaty's approximate solution method for calculating the ordered ranks of importance from the pair-wise ranks is sufficiently accurate for the purpose of this work.

These assumptions are further described and/or justified in the following three sections. 


\subsubsection{Assumed Error in Original Pair-Wise Component Ranks.}

The assumed pdf for the error in the original pair-wise ranks is illustrated in Figure 2. This estimate of the potential error in the expert ranks is based on the author's experience in prior applications $[1,2,3]$ and embodies the following key factors.

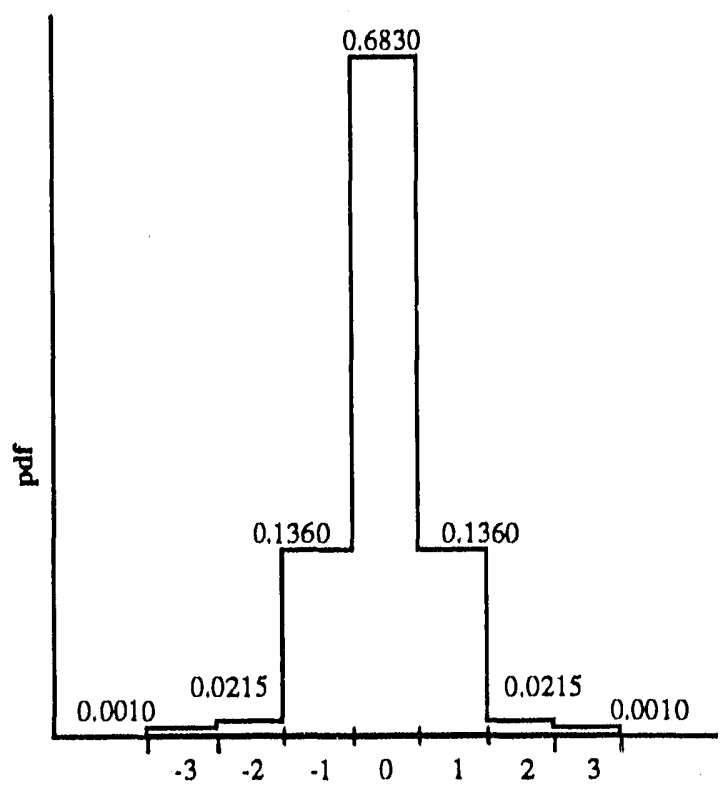

Potential change in best estimate pair-wise ranks

Figure 2. Assumed pdf for potential errors in the original best estimate component pair-wise ranks.

a) It is presumed the pair-wise ranking is conducted in the recommended manner. Namely that the initial ranks are tied to specific experimental evidence to the maximum extent possible. In addition, the resulting AHP component ranks of importance to system behavior are carefully reviewed. In those cases where there may be evidence the results do not reflect the experts' overall judgement, then additional experimental and/or calculational evidence is obtained to support initial or revised pair-wise ranks. Failing this check, then the ranks in question should be escalated in importance until such time as better experimental evidence is available.

b) The assumed discrete pdf is similar to a continuous normal distribution in the sense that zero change in the original BE pair-wise ranks has the same probability as a continuous normal distribution between -1 and +1 standard deviations; a change of zero and \pm 1 in the pair-wise ranks has the same probability as a continuous normal distribution between -2 and +2 standard 
deviations; etc. It may be noted that the probability of $-3 \leq$ change $\leq+3$ is $100 \%$, which is considered conservative with respect to a continuous normal distribution.

It is recognized that the $B E$ pdf of Figure 2 reflects the author's experience from several similar applications of the AHP and is, therefore, somewhat subjective. Therefore, the analyses have been repeated using a second pdf (Figure 3). Again this pdf is based on the author's judgement, however, has the attribute of reducing the probability of zero change and enlarging the probability of changes of $\pm 1, \pm 2$ and \pm 3 in the initial pair-wise ranks, with respect to the BE pdf of Figure 2.

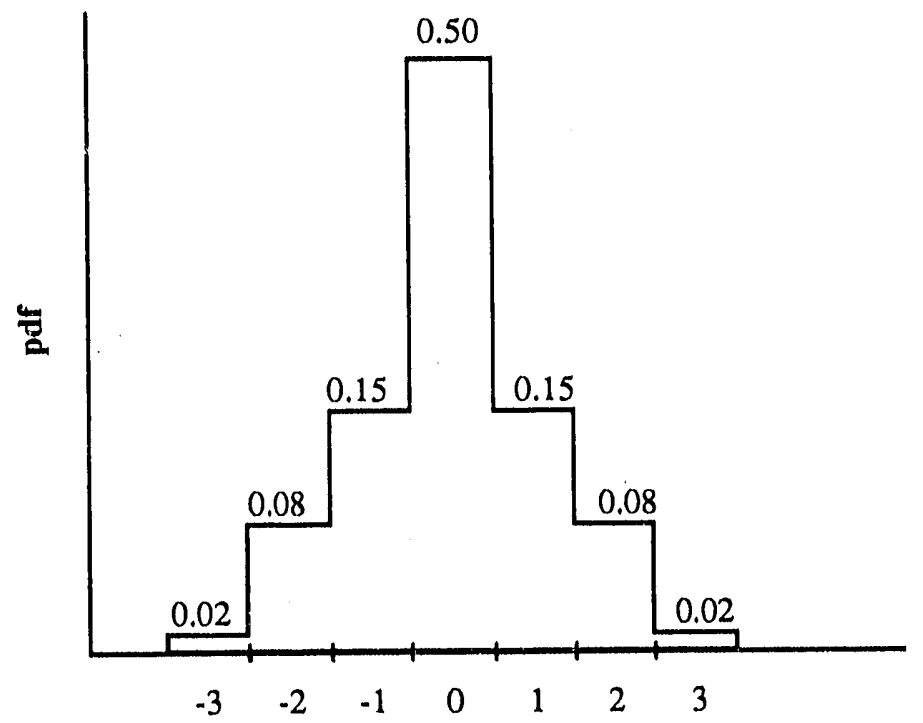

Potential change in best estimate pair-wise ranks

Figure 3. Sensitivity pdf for potential errors in the original best estimate component pair-wise ranks.

\subsubsection{Sufficiency of 10000 Samples.}

The subject sufficiency can be demonstrated by convergence to stable answers in the pdf of the component system importance ranks, and in the actual pdf of the errors (should reflect Figure 2, or Figure 3) applied to the original pair-wise ranks, as the sample size increases. The desired convergence in both of these pdfs is illustrated in Section 4. Appendix B provides additional information.

Even though the results in Section 4 show acceptable convergence at 10000 samples, the possibility exists that the convergence in one run may not be that of another for the identical problem. This possibility arises because the random selection of potential errors is not identical between runs (at least if the random 
selection technique is truly random). Therefore, each of the cases studied included a second run identical to the first, except for the random number sequence. These results are also given in Section 4.

\subsubsection{Sufficiency of Saaty's Approximate Solution.}

Saaty has described two solution methods for the matrix algebra associated with calculating ordered ranks of importance from the pair-wise ranks. The first is iterative and more accurate. The iteration is associated in insuring the optimum solution is achieved even though there may be some inconsistency in the pair-wise ranks. Dimenna based his work on the iterative approach, it being different from Saaty in the relaxation of the need for identical matrices in each level of the hierarchy through a different normalization scheme (Appendix B). The Dimenna approach is the one programmed in the AHP software used by the TRG to obtain their BE results.

Saaty's second method is an approximation of the iterative approach, and has the advantage of a single pass treatment (i.e., a reduced number of algebraic operations). All three methods give identical results for matrices which cre perfectly consistent. In the current work the reduced algebraic operations of the approximate method had a significant attraction because of the several millions of operations necessary for the statistical analysis, and because it is easier to program.

To insure the approximate method was adequate for the purpose of this work, certain studies (Appendix B) were conducted to validate the method and the resulting software. The results from these studies show:

a) The Dimenna and Saaty iterative methods give identical results,

b) The Saaty approximate method gives results identical to the two iterative methods for the highest and lowest ranked components, and to nearly all of the remaining components,

c) The approximate method may give ranks for one or two components which differ from the iterative methods by not more than one (1 to 9 scale).

From these results we conclude the approximate solution method is adequate for the objective. Other information given in Appendix $B$ shows that the approximate solution technique is correctly implemented in the AHP-SA software. 


\section{RESULTING pdfs FOR THE ORIGINAL BE COMPONENT RANKS}

This section summarizes the more significant results of the study; other details are provided in the appendice. The uncertainty results of most interest for the ANSR LBLOCA and decay heat removal scenarios are provided in Section 4.1. Information regarding the validation of the approach is given in Section 4.2. The presentation is concluded with results directed toward exploring the generality of the statistical analysis, in Section 4.3 .

\subsection{Uncertainty in the Original BE Component Importance Ranks}

The results of primary interest to the ANSR are summarized in Tables 2 through 9, which are organized in the following fashion:

\begin{tabular}{||l|c|c|c|c||}
\hline & \multicolumn{2}{|c|}{ LBLOCA } & \multicolumn{2}{c||}{ DECAYHEAT REMOVAL } \\
\cline { 2 - 5 } & $\begin{array}{c}\text { Original } \\
\text { Run }\end{array}$ & $\begin{array}{c}\text { Repeat } \\
\text { Run }\end{array}$ & $\begin{array}{c}\text { Original } \\
\text { Run }\end{array}$ & $\begin{array}{c}\text { Repeat } \\
\text { Run }\end{array}$ \\
\hline $\begin{array}{l}\text { BE pdf for potential error in } \\
\text { original pair-wise ranks }\end{array}$ & Table 2 & Table 3 & Table 6 & Table 7 \\
\hline $\begin{array}{l}\text { Sensitivity pdf for potential } \\
\text { error in original pair-wise } \\
\text { ranks }\end{array}$ & Table 4 & Table 5 & Table 8 & Table 9 \\
\hline
\end{tabular}

In each table, the resulting pdf defining the uncertainty of the original importance of each component (on a scale of 1 to 9) is shown in the upper part of the table. The original importance (ordered rank) is also shown. This data is further summarized in the lower portion of each table, where the original importance level (low, moderate and high) and the probability (\%) of change to another level, based on the uncertainty, is given. The importance level is related to the ordered rank by:

Low importance level $=1$ to 3 ordered rank,

Moderate importance level $=4$ to 6 ordered rank,

High importance level $=7$ to 9 ordered rank.

The importance level probabilities, of the tables are further summarized in Figures 4 and 5 for the $\mathrm{BE}$ and sensitivity pdfs for the potential error in the experts original pair-wise ranks, respectively. In both figures, the probability of no change in the original importance level is shown on the left (a). The probability of a level change of one (high to moderate, moderate to high or low, and low to moderate) is shown on the right (b). The significance of these results follow Figure 5. 
Table 2. Uncertainty in ANSR LBLOCA original component importance based on the BE pdf for the potential error in the original expert pair-wise ranks - Original run.
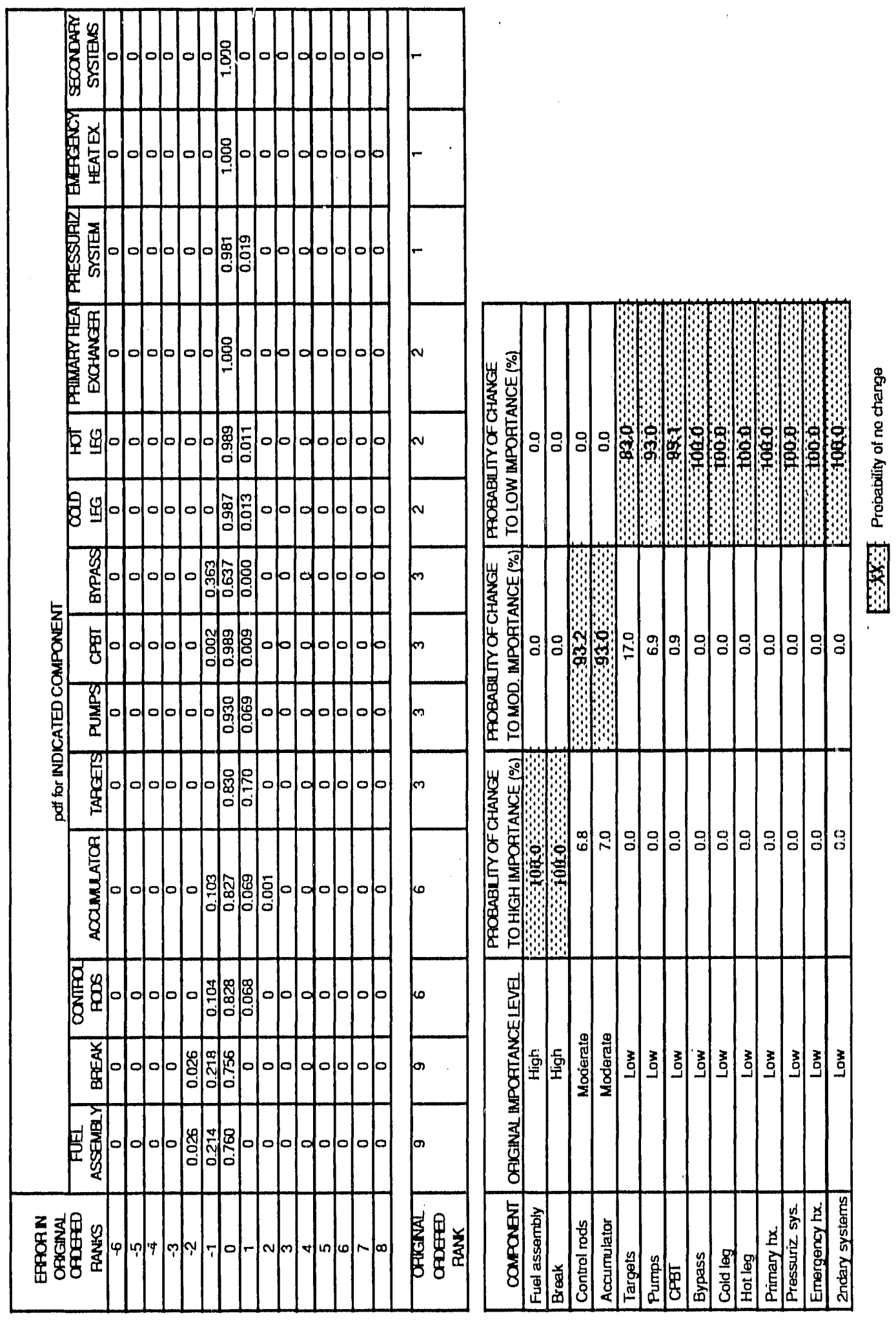
Table 3. Uncertainty in ANSR LBLOCA original component Importance based on the BE pdf for the potentlal error in the original expert pair-wise ranks - Repeat run.
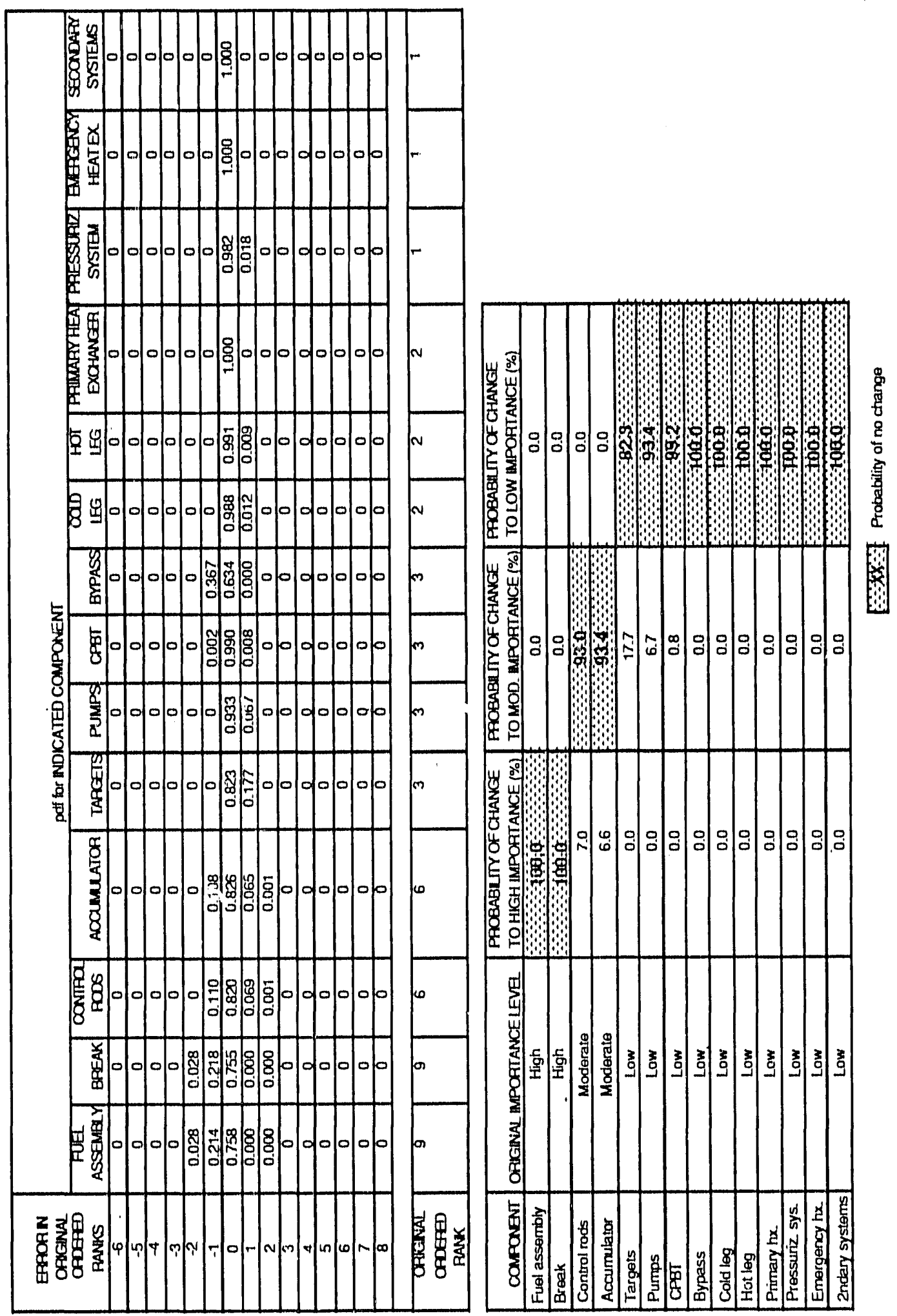
Table 4. Uncertainty in ANSR LBLOCA original component importance based on the sensitivity $p d f$ for the potential error in the original expert palr-wise ranks - Original run.
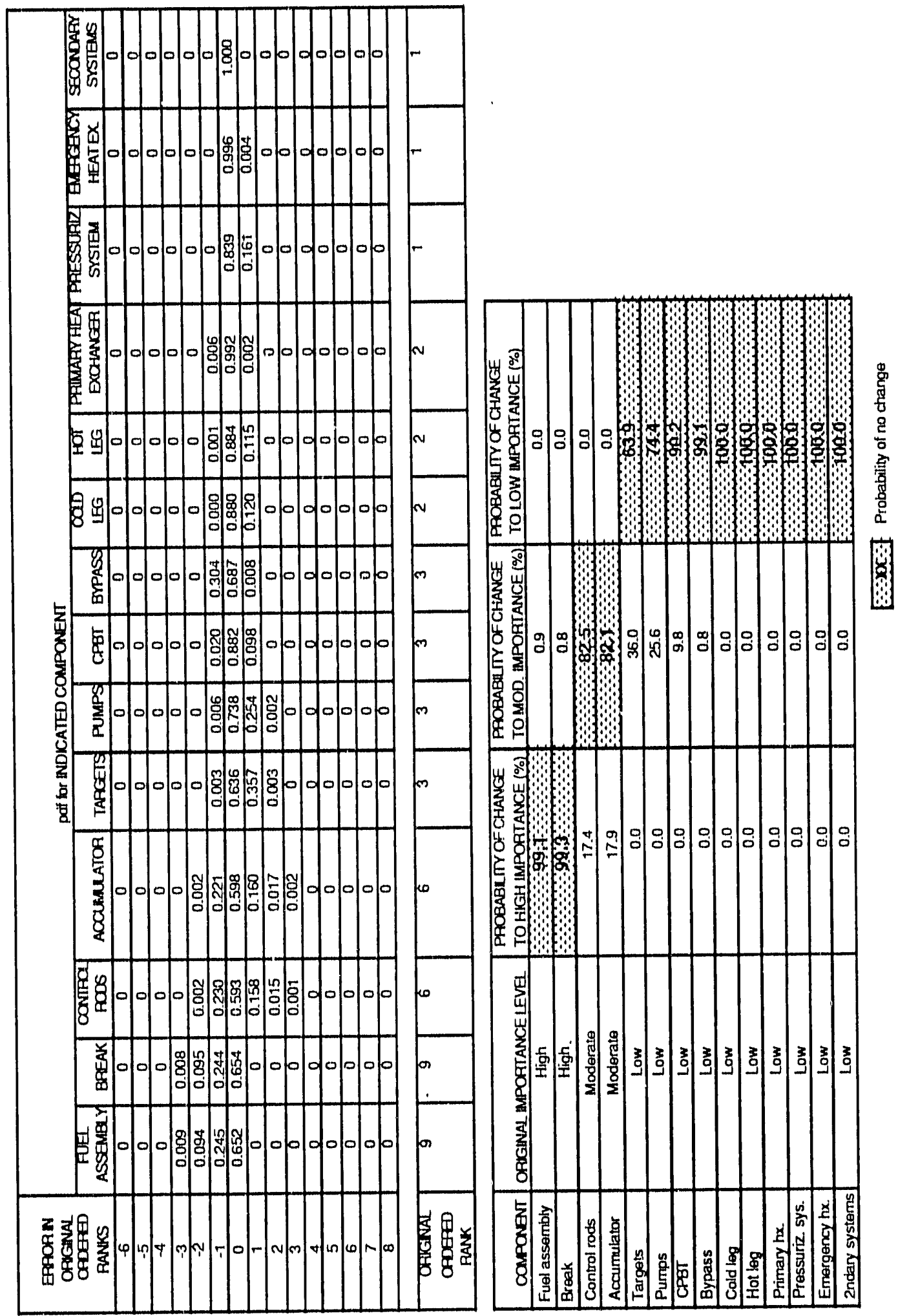
Table 5. Uncertainty in ANSR LBLOCA original component importance based on the sensitivity pdf for the potential error in the original expert pair-wise ranks - Repeat run.
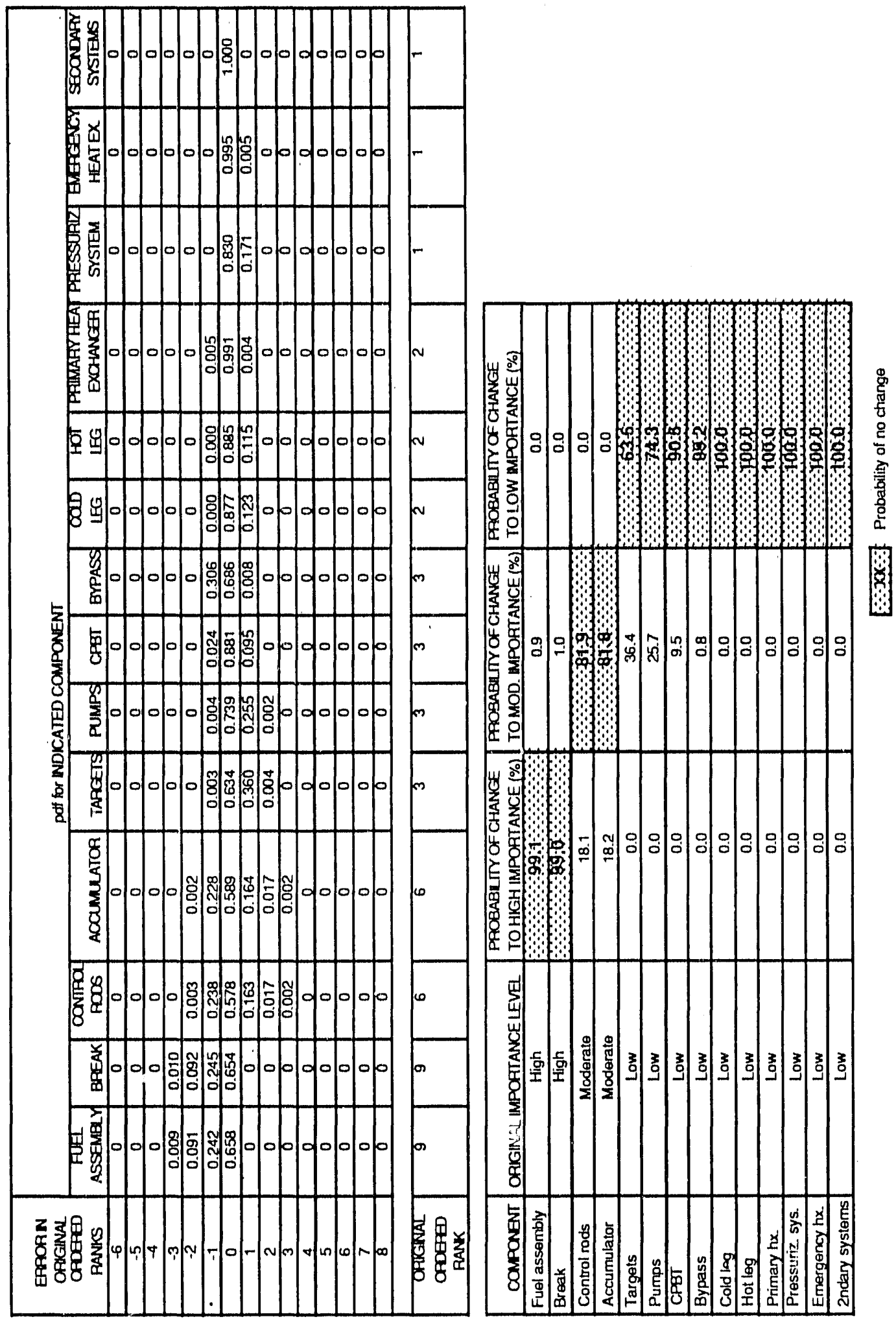
Table 6. Uncertainty in ANSR decay heat removal original component importance based on the BE pdf for the potential error in the original expert pair-wise ranks - Original run.
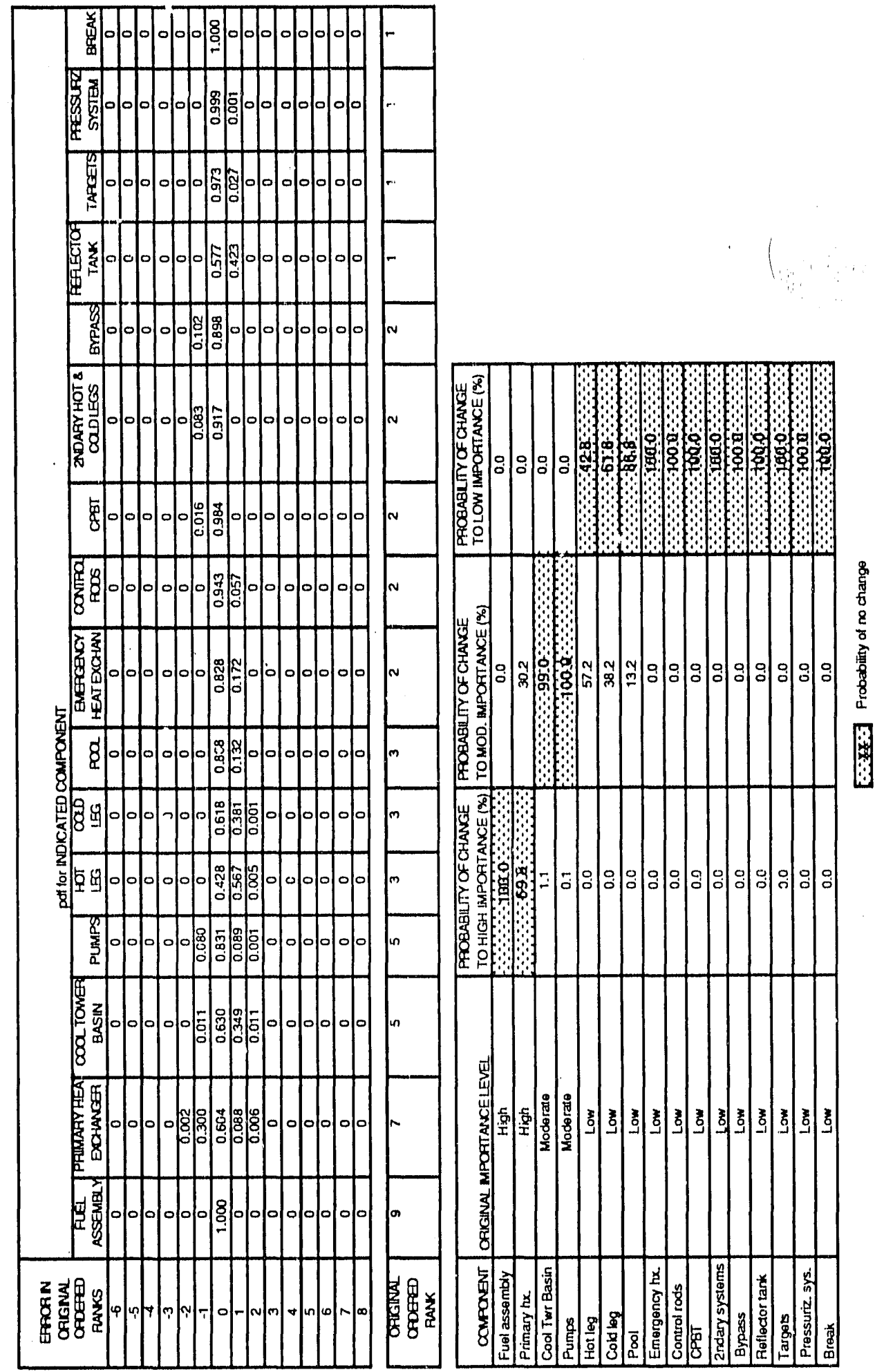
Table 7. Uncertainty in ANSR decay heat removal original component importance based on the BE pdf for the potential error in the original e.pert pair-wise ranks - Repeat run.
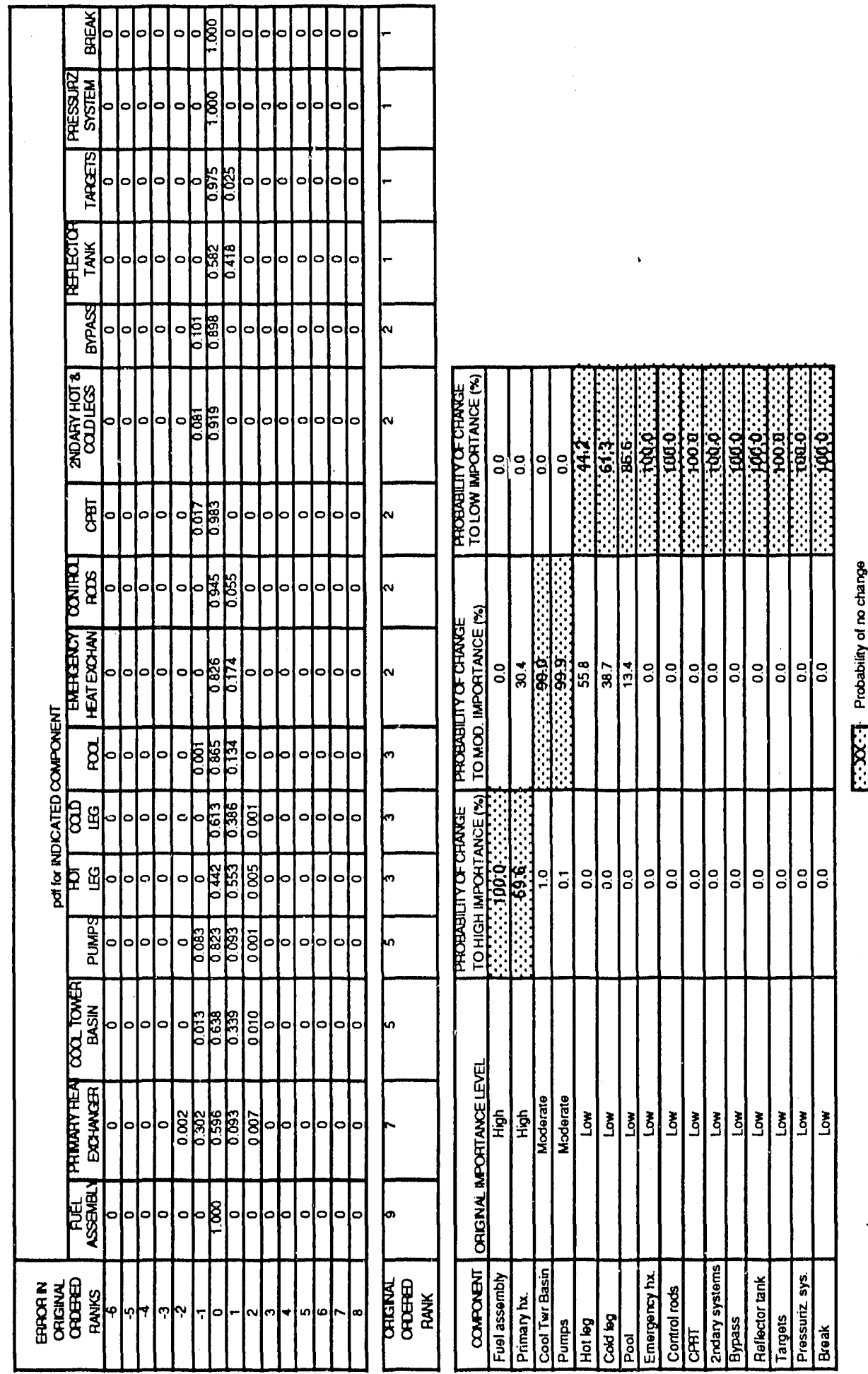
Table 8. Uncertainty in ANSR decay heat removal original component importance based on the sensitivity pdf for the potential error in the original expert pair-wise ranks - Original run.
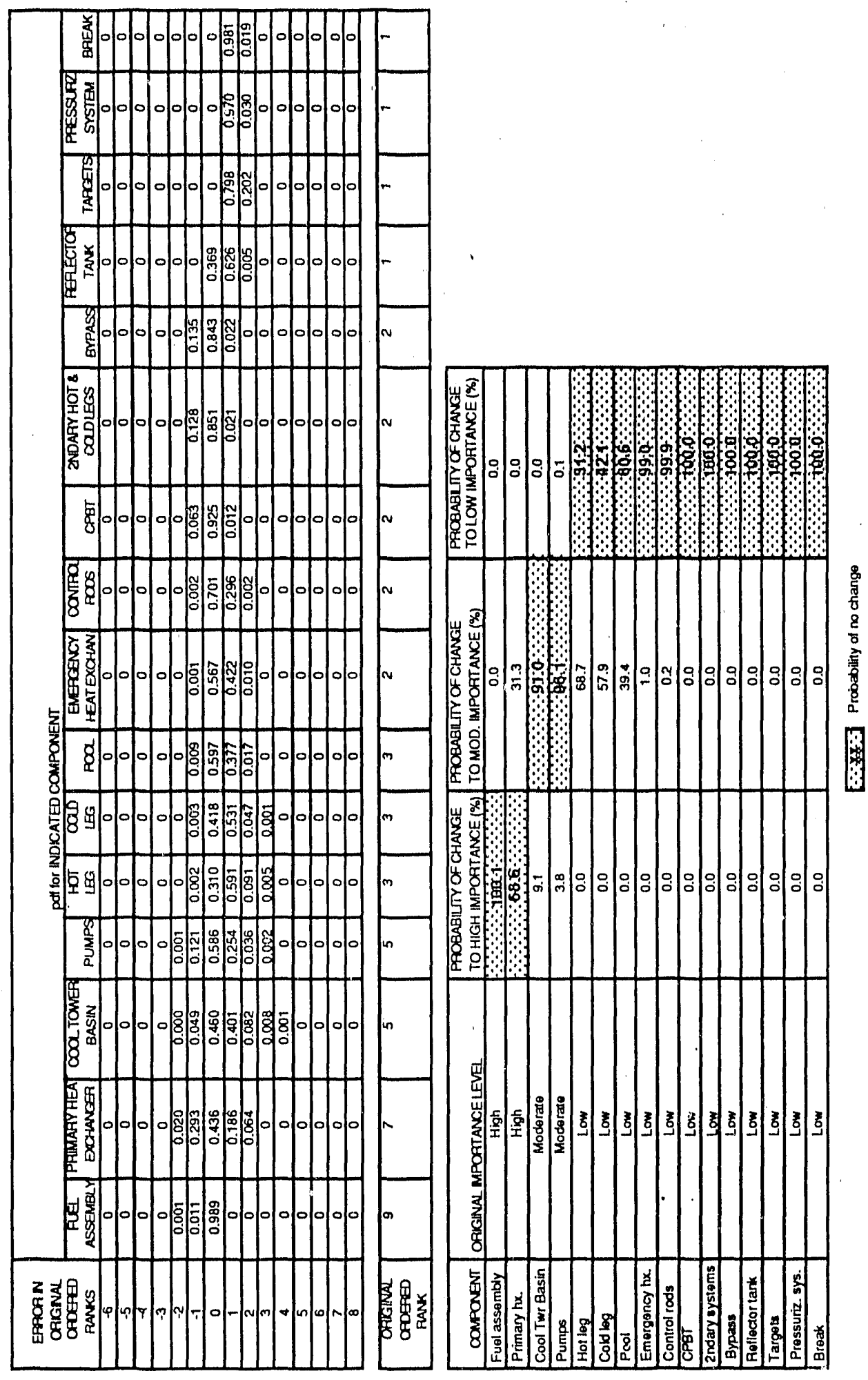
Table 9. Uncertainty in ANSR decay heat removal original component importance based on the sensitivity pdf for the potential error in the original expert pair-wise ranks - Repeat run.

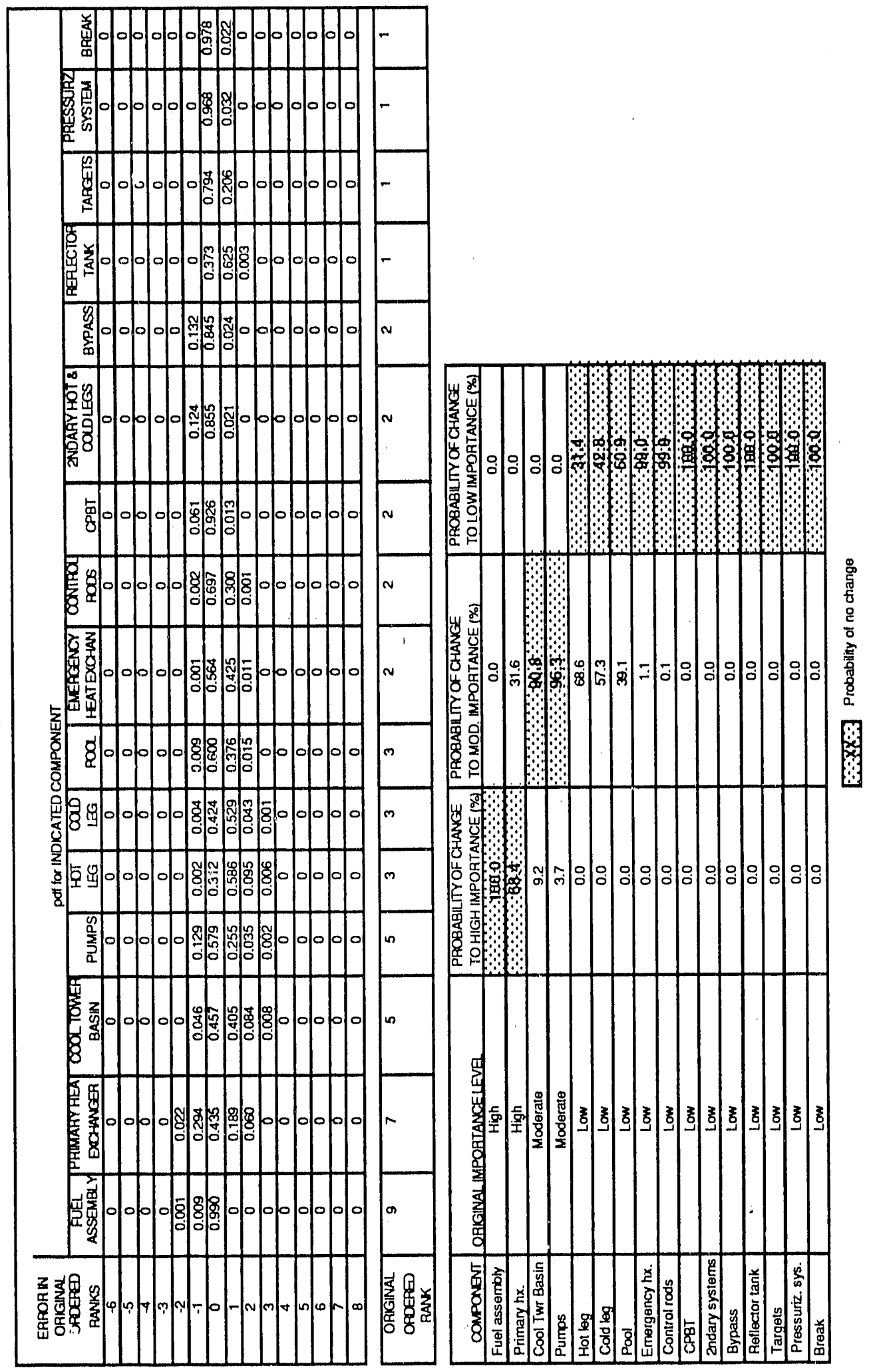


Date base Includes original and tepeat runs for the LBLOCA and decay heat rumoval econariou for $\mathrm{BE}$ pdt

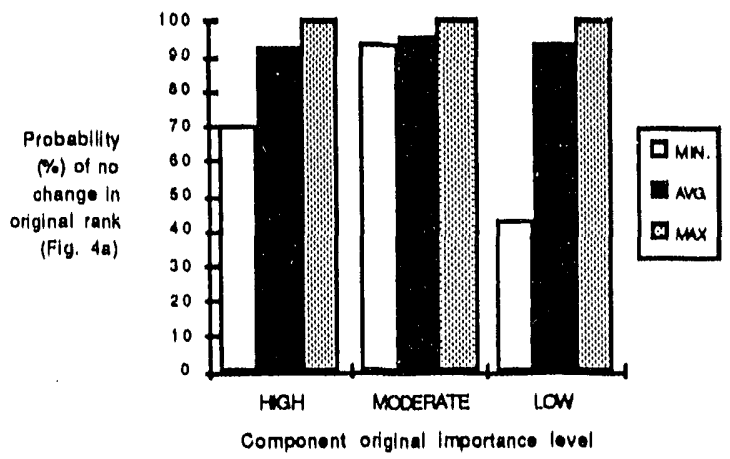

Data base Includes original and repeat runs lor the LBLOCA

arid docay heat removal scenarios for BE pdf

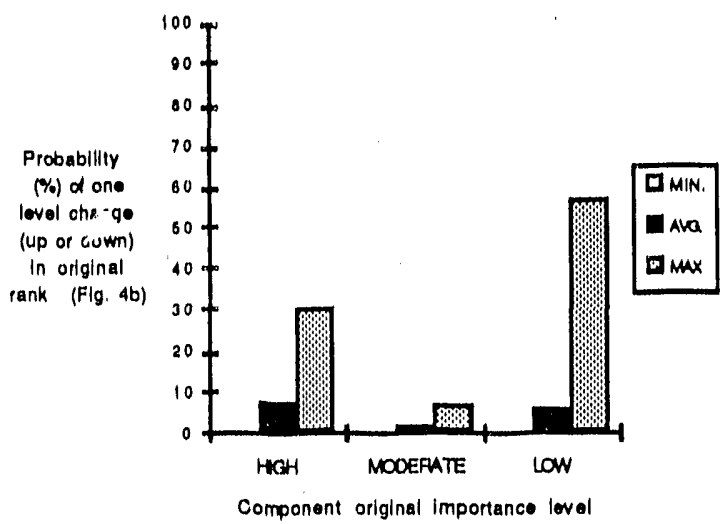

Figure 4. Summary of uncertainty in ANSR original importance levels based on the $B E$ pdf for potential error in experts original pair-wise ranks.

Data base includes original and repeat nus for the LBLOCA and decay heat romoval sconarios for sensitivity pdt

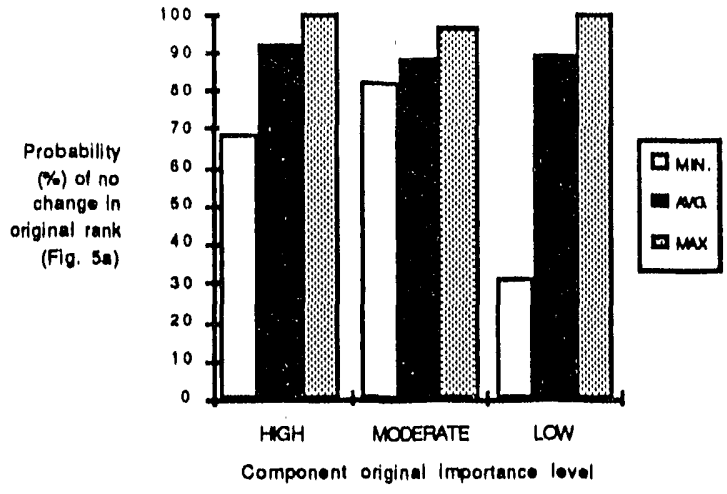

Data base Includes original and repeat runs for the LBLOCA and decay heat removal scenarios for sensitvity pot

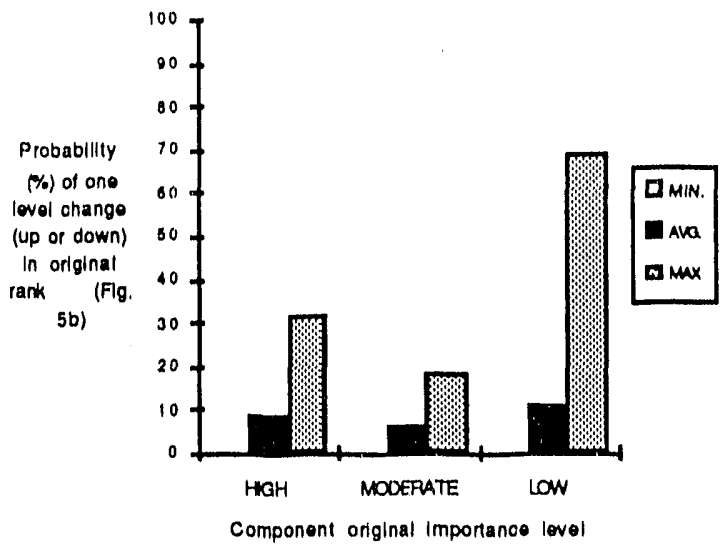

Figure 5. Summary of uncertainty in ANSR original importance levels based on the sensitivity pdf for potential error in experts original pair-wise ranks. 
In the author's opinion, the results of most significance to the objectives of this study are (in decreasing order of importance):

a) There is no probability of importance level changes of two (high to low or low to high), regardless of the transient, potential error pdf, or run. In Figures 4 and 5 the zero change and one level change probabilities add to $100 \%$, allowing no probability for a two level change.

b) On the average, the probability for no change in importance level is greater than $87 \%$, with a corresponding one level change of less than $13 \%$ (average values in Figures 4 and 5), regardless of the transient, potential error pdf, or run.

c) On an individual component basis, the $B E$ no change probability can be as low as $40 \%$ (minimum values in Figure 4) and as high as 100\% (maximum values in Figure 4). The corresponding values for the sensitivity potential error pdf are $30 \%$ and $100 \%$ (Figure 5).

d) On an individual component basis, the $B E$ one level change probability can be as low as 3\% (minimum values in Figure 4) and as high as 58\% (maximum values in Figure 4). The corresponding values for the sensitivity potential error pdf are 5\% and $69 \%$ (Figure 5).

e) The BE probability of no change is relatively independent of the original rank of the component (low, moderate or high) as illustrated in Figure 4a. The corresponding data for the sensitivity pdf show slightly less independence from the original importance level (Figure 5a).

f) The probability of one level change is significantly more dependent on the original importance level for both potential error pdfs. In reducing the data the author has noted an increased tendency for importance level switching when the original ordered rank is near the boundary between the levels (i.e., 6-7 and 4-3 in the 1 to 9 scale). In the author's opinion this is not a surprising result.

From the above results, the author concludes the AHP, when applied as recommended, is a robust methodology with which to determine the ANSR component (and by extension, phenomena) importance.

\subsection{Validation of the Approach and Software}

The results related to validation of the approach and software are summarized in this section. The repeatability of the results is discussed in Section 4.2.1. 
Convergence of the results with increasing Monte Carlo cample size is covered in Section 4.2.2.

\subsubsection{Repeatability of Results}

The original and repeat ANSR uncertainty data of Tables 2 through 9 are replotted in Figures 6 and 7 for the BE and sensitivity potential error pdfs, respectively. These data show no significant difference between the original and repeat runs. The maximum difference is $1.4 \%$, which occurs in the BE potential error runs at the

minimum comparison for zero change, and the maximum comparison for a change of one level in importance.
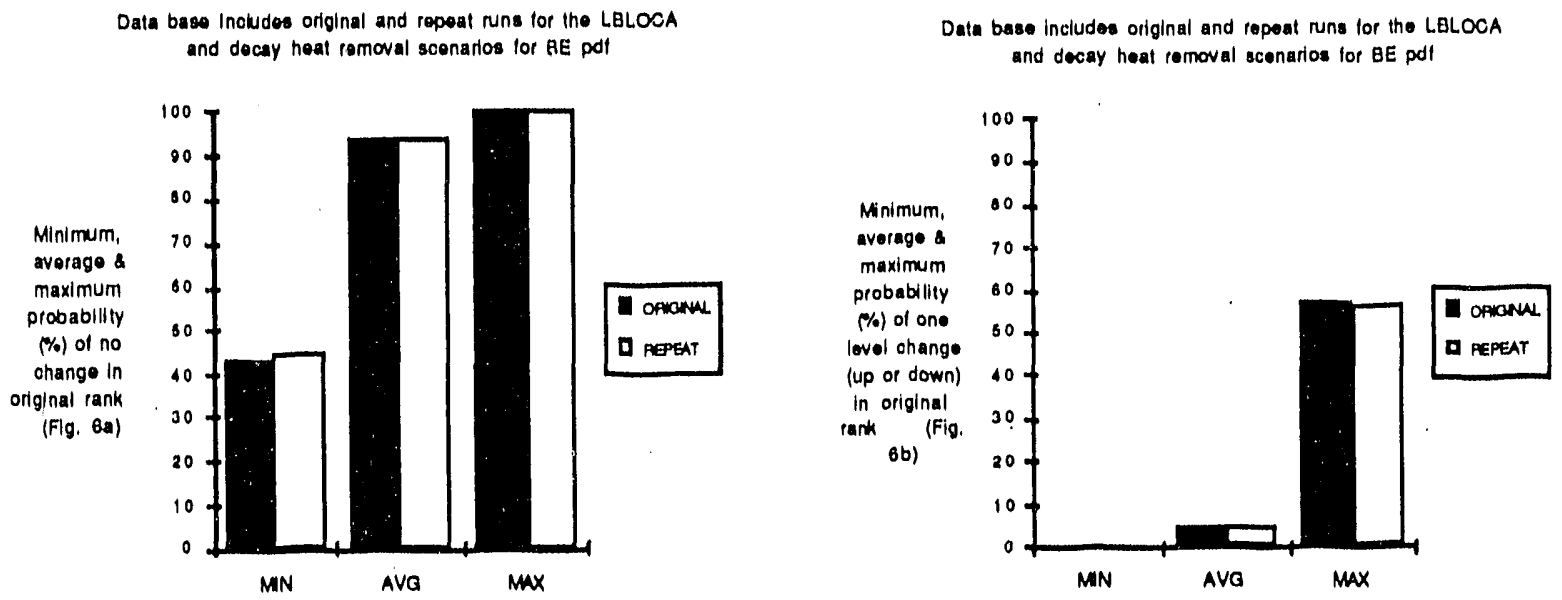

Figure 6. Comparison of ANSR BE original and repeat run importance levels.
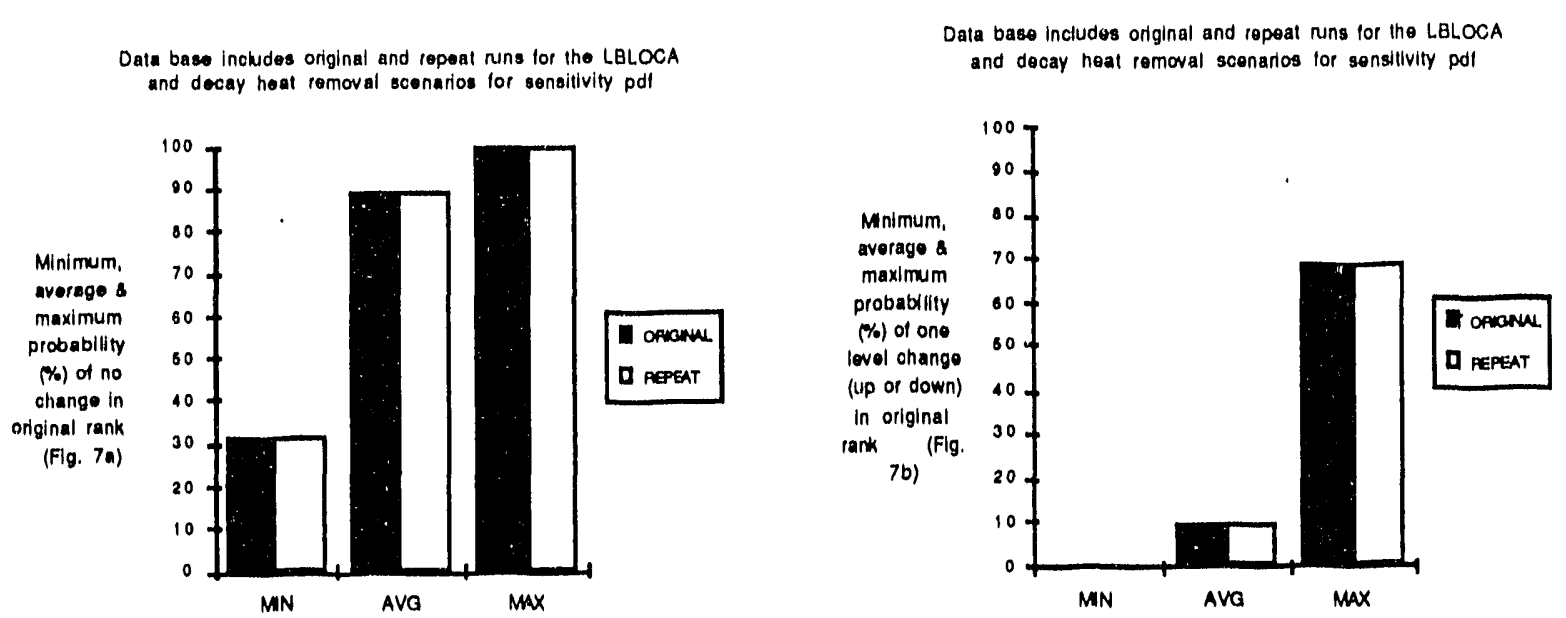

Figure 7. Comparison of ANSR sensitivity original and repeat run importance levels. 


\subsubsection{Acceptable Convergence in ANSR Analysis at 10000 Monte Carlo Samples}

The convergence is illustrated in Figures 8 and 9 for the ANSR analysis. An additional perspective is provided in Appendix $B$.

At 10000 samples the average of the actual pdf's resulting from random selection of the potential error in pair-wise ranks from the specifted potential error pdf is essentially identical to the specified pdf (Figures $8 \mathrm{a}$ and 9a). The difference in any actual potential error pdfs from the specified pdf is also small as illustrated by the minimum and maximum actual potential error pdfs (Figures $8 \mathrm{a}$ and $9 \mathrm{a}$ ).

The average uncertainty pdfs of the original ordered ranks of the components, normalized to that at 10000 samples, remains essentially equal to one for sample sizes greater than 2000 (Figures $8 \mathrm{~b}$ and $9 \mathrm{~b}$ ). The minimum and maximum normalized uncertainty pdfs decrease with increasing sample size, with the minimum and maximum for sample sizes larger than 9500 being within $\pm 5 \%$ of that at 10000 samples for the BE pdf, and within $+5 \%$, - $10 \%$ of that at 10000 samples for the sensitivity pdf.

Given the above results, and the relative insensitivity of the probability of change in the importance level of the original ordered ranks with the assumed potential error pdf as shown in Figures 4 and 5, it is concluded a sample size of 10000 is sufficient for the objectives of this study.

\subsection{Generality of the ANSR Statistical Results}

Appendix B provides information related to the validation of the Saaty iterative, Saaty approximate, and Dimenna iterative methods of matrix solutions of the pairwise ranking to determine the ordered rank. The validation includes an original problem solved by Saaty which has fewer matrix elements. This problem (referred to as problem 103) has been analyzed in the same statistically based way, as was the ANSR component ranking, to gain an insight of the potential sensitivity of the AHP to matrix size. The results for the Saaty problem are summarized in Tables 10 through 13. That data is further summarized in Figures 10 and 11, respectively, for the $B E$ and sensitivity pdfs of the potential error in the original pair-wise ranks. Figures $10 \mathrm{a}$ and $11 \mathrm{a}$ show there is a decreased probability of zero change in the original importance levels, on the average, for the Saaty problem versus the ANSR results. This is accompanied with an increase in the average probability for a change of one importance level (up or down), again with respect to the ANSR results. In addition, the Saaty results show a small probability (less than 5\%) that low ranked items might 
Data base inoludes all components for orlginal \& repeat runs of the ANSR LBLOCA \& decay heat removal scenarlos using the BE potentlal error pdf

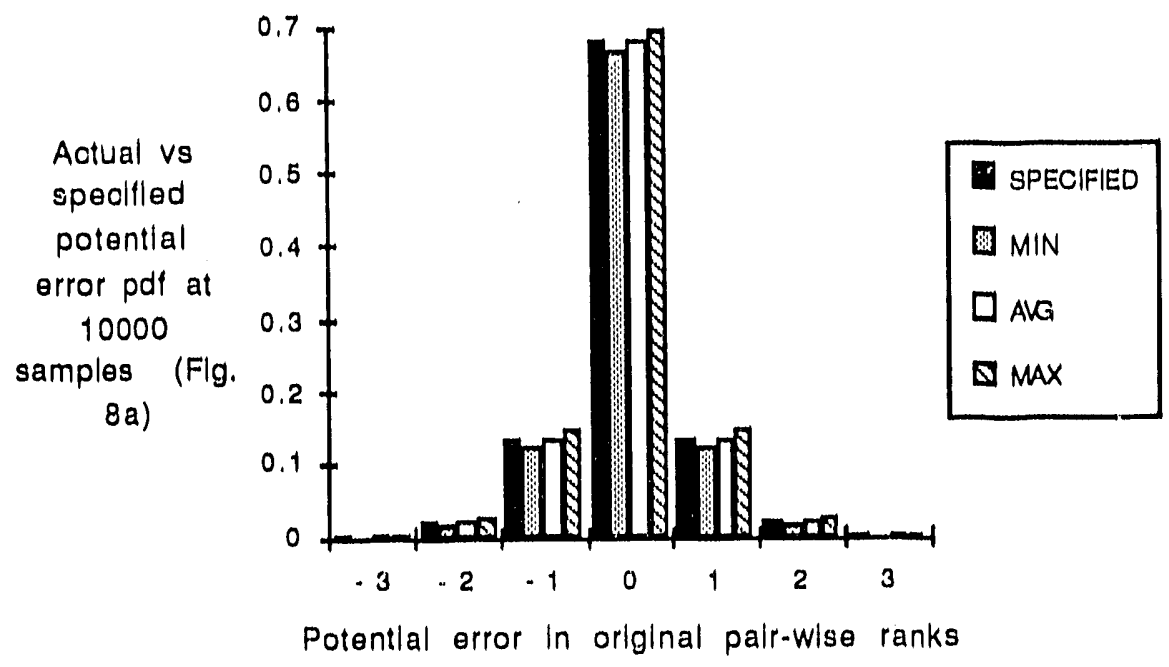

Data base Inoludes all components for orlginal \& repeat runs of the ANSR LBLOCA \& decay heat removal scenarios using the BE potentlal error pdf

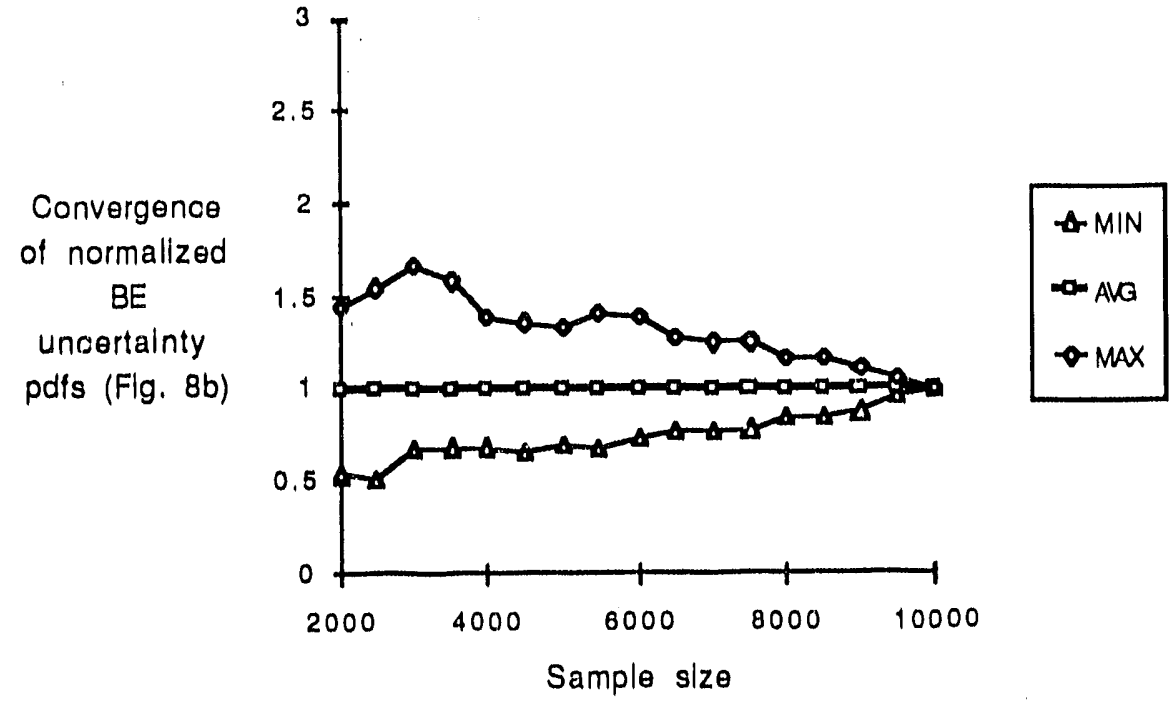

Figure 8. Illustration of the convergence of the BE ANSR uncertainty runs. 
Data base Inoludes all oomponents for original \& repeat runs of the ANSR LBLOCA \& deoay heat removal scenarlos using the sensitlvity potential error pdf

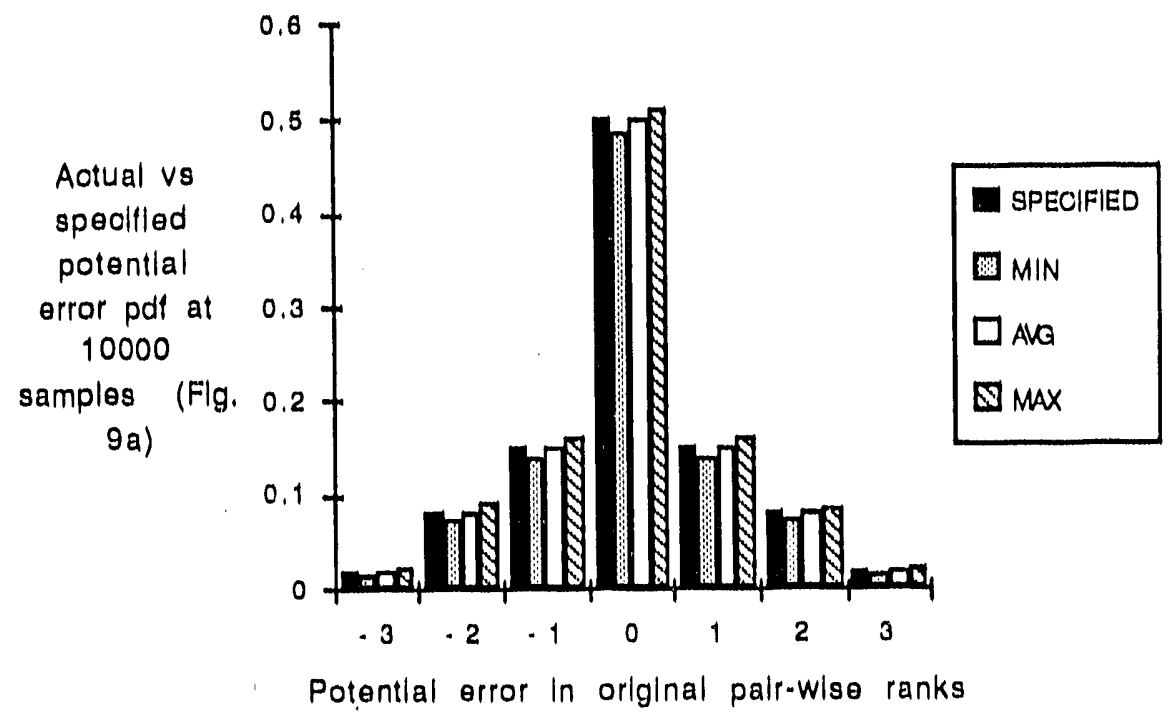

Data base Includes all components for original \& repeat runs of the ANSA LBLOCA \& decay heat removal soenarlos using the sensitivity potentlal error pdf

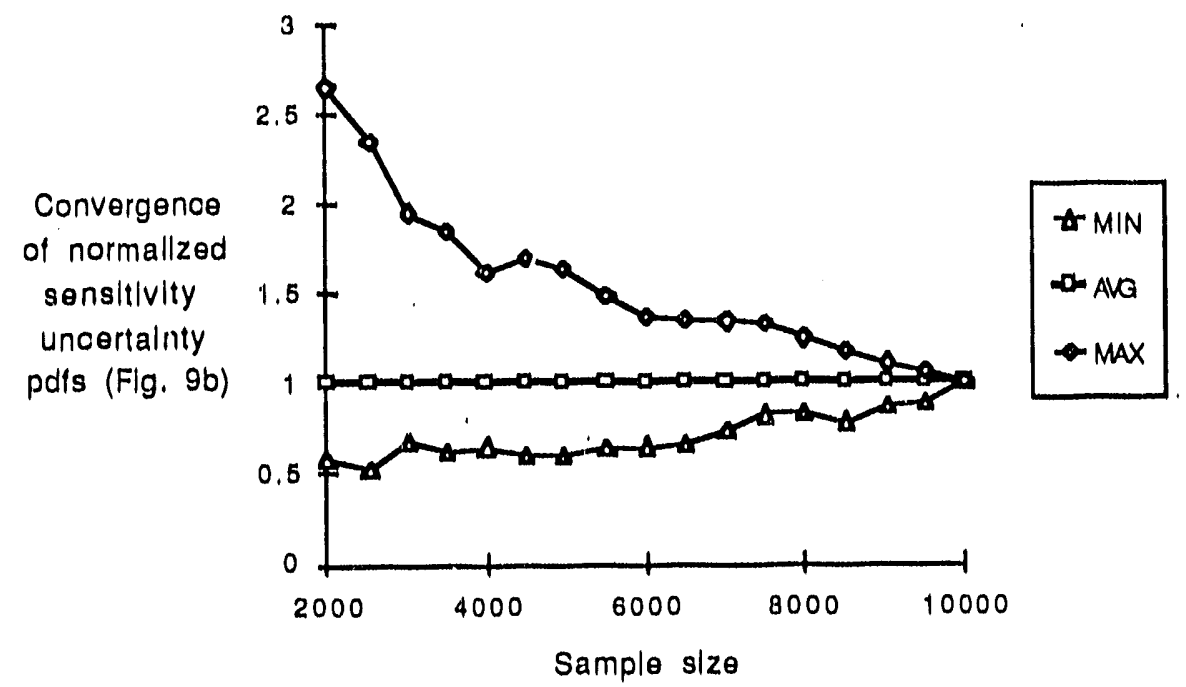

Figure 9. Illustration of the convergence of the sensitivity ANSR uncertainty runs. 
Table 10. Uncertainty in Saaty problem 103 original component Importance based on the BE pdf for the potential error in the original expert pairwwise ranks Original run.

\begin{tabular}{|c|c|c|c|c|c|c|}
\hline \multirow{2}{*}{$\begin{array}{l}\text { ERROR IN } \\
\text { ORIGINAL } \\
\text { ORDERED } \\
\text { FANKS }\end{array}$} & \multicolumn{6}{|c|}{ pdf for INDIOATED ATTAIBUTE } \\
\hline & Pploe & Integrlty & Absorptlveness & Slze & Softness & Deslgn \\
\hline .6 & 0 & 0 & 0 & 0 & 0 & 0 \\
\hline-5 & 0 & 0 & 0 & 0 & 0 & 0 \\
\hline .4 & 0,001 & 0 & 0 & 0 & 0 & 0 \\
\hline .3 & 0.008 & 0.008 & 0 & 0 & 0 & 0 \\
\hline .2 & 0.020 & 0.091 & 0.015 & 0 & 0 & 0 \\
\hline-1 & 0.038 & 0.294 & 0.152 & 0.039 & 0,017 & 0 \\
\hline 0 & 0.933 & 0.310 & 0.393 & 0.442 & 0.514 & 1.000 \\
\hline 1 & 0 & 0.164 & 0.265 & 0.384 & 0.410 & 0 \\
\hline 2 & 0 & 0,133 & 0.108 & 0.104 & 0.053 & 0 \\
\hline 3 & 0 & 0 & 0.041 & 0.023 & 0.006 & 0 \\
\hline 4 & 0 & 0 & 0.025 & 0.005 & 0 & 0 \\
\hline 5 & 0 & 0 & 0 & 0 & 0 & 0 \\
\hline$\theta$ & 0 & 0 & 0 & 0 & 0 & 0 \\
\hline 7 & 0 & 0 & 0 & 0 & 0 & 0 \\
\hline 8 & 0 & 0 & 0 & 0 & 0 & 0 \\
\hline $\begin{array}{c}\text { OAIGINAL } \\
\text { OPDERED } \\
\text { RANK }\end{array}$ & 9 & 5 & 4 & 3 & 2 & 1 \\
\hline
\end{tabular}

\begin{tabular}{|c|c|c|c|c|}
\hline ATTRIBUTE & $\begin{array}{l}\text { ORIGINAL } \\
\text { IMPORTANCE } \\
\text { LEVEL }\end{array}$ & $\begin{array}{l}\text { PROBABILITY } \\
\text { OFCHANGE } \\
\text { TOHIGH } \\
\text { MMPORTANCE \% }\end{array}$ & $\begin{array}{l}\text { PROBABILITY } \\
\text { OFCHANGE } \\
\text { TOMODERATE } \\
\text { IMPORTANCE \% }\end{array}$ & $\begin{array}{l}\text { PROBABILITY } \\
\text { OFCHANCE } \\
\text { TOLOW } \\
\text { IMPORTANCE } \%\end{array}$ \\
\hline Prloo & Hlgh & 40 & 0.9 & 0.0 \\
\hline Integrity & Moderate & 13,3 & 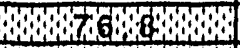 & 9,9 \\
\hline Absorptlveness & Moderate & 6.6 & 6006to6 & 16.7 \\
\hline Size & Low & 0.6 & 51.1 & 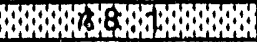 \\
\hline Softness & Low & 0.0 & 0.0 & a:4000 \\
\hline Design & Low & 0.0 & 0.0 & ONondo \\
\hline
\end{tabular}


Table 11. Uncertainty in Saaty problem 103 original component importance based on the BE pdf for the potentlal crror In the original expert pair-wise ranks " Repeat run.

\begin{tabular}{|c|c|c|c|c|c|c|}
\hline \multirow{2}{*}{$\begin{array}{l}\text { ERROR IN } \\
\text { ORIOINAL } \\
\text { OFDERED } \\
\text { RANKS }\end{array}$} & \multicolumn{6}{|c|}{ pd for INDICATED ATTRIBUTE } \\
\hline & Prlog & $\ln t e g r l t y$ & Absorpllveness & Slze & Softness & Doslgn \\
\hline .6 & 0 & 0 & 0 & 0 & 0 & 0 \\
\hline .5 & 0 & 0 & 0 & 0 & 0 & 0 \\
\hline .4 & 0,002 & 0 & 0 & 0 & 0 & 0 \\
\hline .3 & 0.011 & 0.001 & 0.005 & 0 & 0 & 0 \\
\hline .2 & 0.028 & 0.042 & 0.100 & 0 & 0 & 0 \\
\hline .1 & 0,060 & 0.218 & 0.339 & 0,030 & 0.015 & 0 \\
\hline 0 & 0.899 & 0,347 & 0.327 & 0.466 & 0.579 & 1.000 \\
\hline 1 & 0 & 0.204 & 0.142 & 0.378 & 0.363 & 0 \\
\hline 2 & 0 & 0.189 & 0.055 & 0.098 & 0.039 & 0 \\
\hline 3 & 0 & 0 & 0.033 & 0,022 & 0,005 & 0 \\
\hline 4 & 0 & 0 & 0 & 0.055 & 0.001 & 0 \\
\hline 5 & 0 & 0 & 0 & 0.001 & 0 & 0 \\
\hline$\theta$ & 0 & 0 & 0 & 0 & 0 & 0 \\
\hline 7 & 0 & 0 & 0 & 0 & 0 & 0 \\
\hline 8 & 0 & 0 & 0 & 0 & 0 & 0 \\
\hline $\begin{array}{c}\text { OAIGINAL } \\
\text { OPDERED } \\
\text { RANK }\end{array}$ & 9 & 5 & 4 & 3 & 2 & 1 \\
\hline
\end{tabular}

\begin{tabular}{|c|c|c|c|c|}
\hline ATTR & $\begin{array}{l}\text { ORIGINAL } \\
\text { IMPORTANCE } \\
\text { LEVEL }\end{array}$ & $\begin{array}{l}\text { PAOBABILITY } \\
\text { OFCHANGE } \\
\text { TOHIGH } \\
\text { IMPOATANCE \% }\end{array}$ & $\begin{array}{l}\text { PROBABILITY } \\
\text { OFCHANGE } \\
\text { TOMODERATE } \\
\text { IMPORTANCE } \%\end{array}$ & $\begin{array}{l}\text { PROBABILITY } \\
\text { OFCHLNCE } \\
\text { TOLOW } \\
\text { MMPOATANCE \% }\end{array}$ \\
\hline Price & Hlgh & (W's & 1,3 & 0.0 \\
\hline Integrity & Moderate & 18.9 & 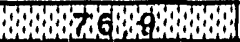 & 4,3 \\
\hline Absorptiveness & Moderale & 3.3 & 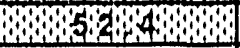 & 44.4 \\
\hline Slze & Low & 5.6 & 49.8 & R日906 \\
\hline Softness & Low & 0.0 & 4.5 & 2509 \\
\hline Deslgn & Low & 0.0 & 0.0 & 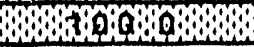 \\
\hline
\end{tabular}


Table 12. Uncertainty in Saaty problem 103 orlginal component Importance based on the sensitivity pdf for the potential error in the original expert pair-wlse ranks - Original run.

\begin{tabular}{|c|c|c|c|c|c|c|}
\hline \multirow{2}{*}{$\begin{array}{c}\text { EAFOA IN } \\
\text { ORIOINAL } \\
\text { OPDERED } \\
\text { RANKS }\end{array}$} & \multicolumn{6}{|c|}{ pdl for INDIOATED ATTRIBUTE } \\
\hline & Prloo & Integrity & Aboorptlveness & SIze & Sottness & Design \\
\hline .6 & 0.001 & 0 & 0 & 0 & 0 & 0 \\
\hline .5 & 0.006 & 0 & $\overline{0}$ & 0 & 0 & 0 \\
\hline 4 & 0.023 & 0,003 & 0,003 & 0 & 0 & 0 \\
\hline .3 & 0.050 & 0.031 & 0.046 & 0 & 0 & 0 \\
\hline .2 & 0.075 & 0,109 & 0,173 & 0,012 & 0 & 0 \\
\hline .1 & 0.103 & 0.198 & 0.250 & 0.111 & 0.079 & 0 \\
\hline 0 & 0.741 & 0.200 & 0.216 & 0.351 & 0.441 & 0.994 \\
\hline 1 & 0 & 0.163 & 0.134 & 0.286 & 0.332 & 0.006 \\
\hline 2 & 0 & 0.296 & 0.075 & 0.139 & 0.106 & 0 \\
\hline 3 & 0 & 0 & 0.102 & 0.065 & 0.031 & 0 \\
\hline 4 & 0 & 0 & 0 & 0.024 & 0.009 & 0 \\
\hline 5 & 0 & 0 & 0 & 0.008 & 0,002 & 0 \\
\hline 6 & 0 & 0 & 0 & 0.004 & 0 & 0 \\
\hline 7 & 0 & 0 & 0 & 0 & 0 & 0 \\
\hline 8 & 0 & 0 & 0 & 0 & 0 & $n$ \\
\hline $\begin{array}{l}\text { ORIGINAL } \\
\text { OPDERED } \\
\text { RANK }\end{array}$ & 9 & 5 & 4 & 3 & 2 & 1 \\
\hline
\end{tabular}

\begin{tabular}{|l|c|c|c|c|}
\hline & $\begin{array}{c}\text { ORIGINAL } \\
\text { IMPORTANCE } \\
\text { LEVEL }\end{array}$ & $\begin{array}{c}\text { PROBABILITY } \\
\text { OFCHANCE } \\
\text { TOHIGH } \\
\text { IMPORTANCE \% }\end{array}$ & $\begin{array}{c}\text { PROBABILITY } \\
\text { OF CHANCE } \\
\text { TOMODERATE } \\
\text { IMPORTANCE \% }\end{array}$ & $\begin{array}{c}\text { PROBABILITY } \\
\text { OFCHANCE } \\
\text { TOLOW }\end{array}$ \\
IMPORTANCE \%
\end{tabular}

Probabillty of no change 
Table 13. Uncertainty in Saaty problem 103 ortginal component importance based on the sensitivity pdf for the potential error in the original expert pair-wise ranks - Repeat run.

\begin{tabular}{|c|c|c|c|c|c|c|}
\hline \multirow{2}{*}{$\begin{array}{l}\text { ERRORIN } \\
\text { ORIGINAL } \\
\text { ORDERED } \\
\text { RANKS }\end{array}$} & \multicolumn{6}{|c|}{ pdf for INDICATED ATTRIBUTE } \\
\hline & Prloe & Integrify & Absorptlveness & SIze & Softness & Design \\
\hline .6 & 0 & 0 & 0 & 0 & 0 & 0 \\
\hline .5 & 0.008 & 0 & 0 & 0 & 0 & 0 \\
\hline .4 & 0.022 & 0.003 & 0.003 & 0 & 0 & 0 \\
\hline .3 & 0.048 & 0.029 & 0.047 & 0 & 0 & 0 \\
\hline-2 & 0.077 & 0,110 & 0.167 & 0.010 & 0 & 0 \\
\hline .1 & 0.098 & 0.189 & 0.245 & 0.111 & 0.080 & 0 \\
\hline 0 & 0.747 & 0.211 & 0.209 & 0.344 & 0.450 & 0.994 \\
\hline$\frac{1}{1}$ & 0 & 0.164 & 0.146 & 0.292 & 0.322 & 0.006 \\
\hline$\overline{2}$ & $\overline{0}$ & 0.295 & 0.081 & 0.140 & 0.104 & 0 \\
\hline 3 & $\overline{0}$ & 0 & 0.102 & 0.066 & 0.033 & 0 \\
\hline 4 & 0 & 0 & 0 & 0.024 & 0.009 & 0 \\
\hline 5 & 0 & $\overline{0}$ & $\overline{0}$ & 0.009 & 0.002 & 0 \\
\hline 6 & $\overline{0}$ & 0 & $\overline{0}$ & 0.005 & 0.001 & 0 \\
\hline 7 & 0 & 0 & 0 & 0 & 0 & 0 \\
\hline 8 & 0 & 0 & 0 & 0 & 0 & 0 \\
\hline $\begin{array}{c}\text { ORIGINAL } \\
\text { ORDERED } \\
\text { RANK }\end{array}$ & 9 & 5 & 4 & 3 & 2 & 1 \\
\hline
\end{tabular}

\begin{tabular}{|c|c|c|c|c|}
\hline & $\begin{array}{l}\text { ORIGINAL } \\
\text { IMPORTANCE }\end{array}$ & $\begin{array}{l}\text { PAOBABILITY } \\
\text { OFCHANCE } \\
\text { TOHIGH }\end{array}$ & $\begin{array}{l}\text { PROBABILITY } \\
\text { OF CHANCE } \\
\text { TOMODERATE } \\
\text { IMPORTANCE }\end{array}$ & $\begin{array}{l}\text { PROBABILITY } \\
\text { OFCHANGE } \\
\text { TOLOW } \\
\text { IMPOATANCE \% }\end{array}$ \\
\hline ATTRIBUTE & LEVEL & IMPORTANCE \% & IMPORTANCE $\%$ & IMPORTANCE $\%$ \\
\hline Prlce & Hlgh & 92.22 & 7.8 & 0.0 \\
\hline Integrlty & Moderate & 29.5 & 56.39 & 14.1 \\
\hline Absorptlveness & Moderate & 10.2 & 43.6 & 46.2 \\
\hline$S \mid z \theta$ & Low & 3,8 & 49,8 & 46.45 \\
\hline Softness & Low & 0.3 & 14.6 & $85 \% 2$ \\
\hline Design & Low & 0.0 & 0.0 & 100.0 \\
\hline
\end{tabular}




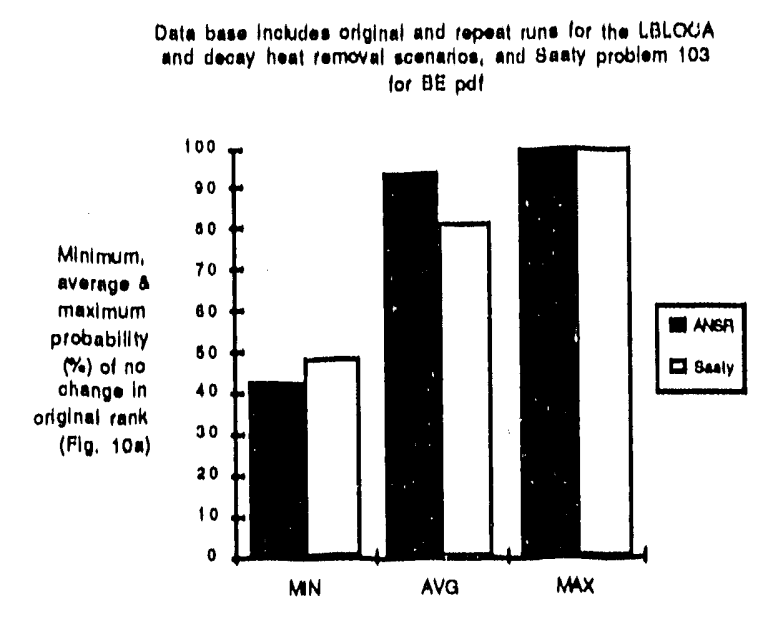
Data bace Inoludes original and repeat run for the Lel.OOA and decay heat removal conarion, and sasty prodom 103 lot $\mathrm{BE}$ pedt

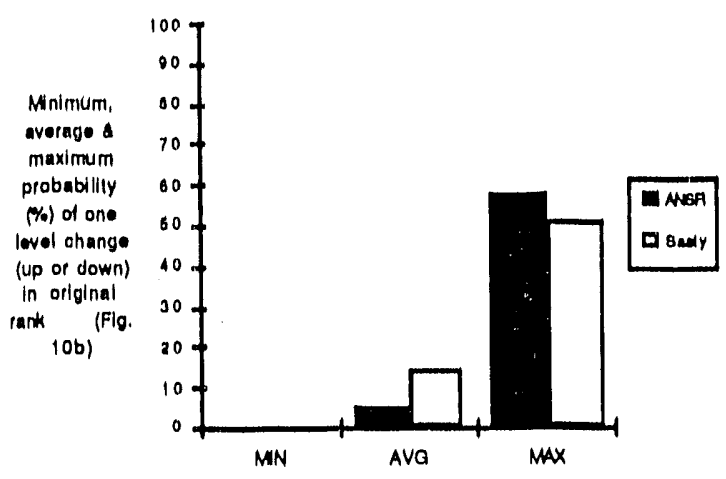

Data base Inoludes original and repeal runs for the L.BLOCA and decay heat removal scenarios, and Saaty problem 103 for BE pdl

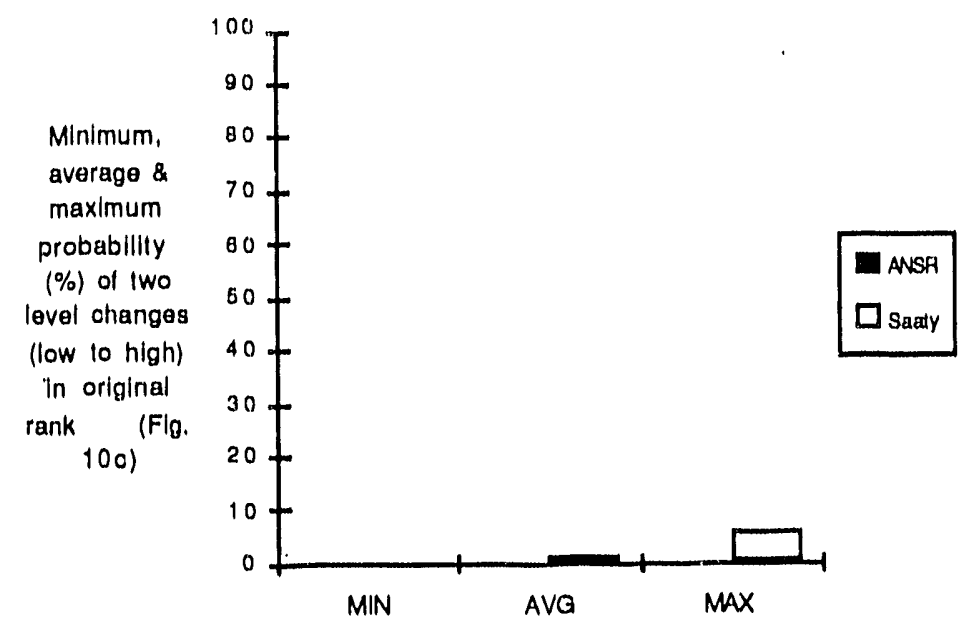

Figure 10. Comparison of ANSR and Saaty problem 103 BE importance levels. 
Date base incivdes original and repeat runs for the LBLOCA and decay heat removal aconarios, and Santy problem 103 for sonaitivity pdt

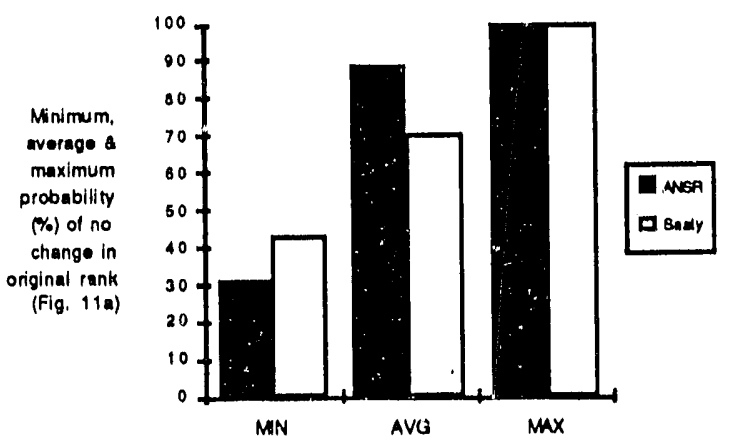

Date base Includes original and repeat runs for the LBLOCA and decay heat romoval scenarios, and Saaty roblom 103 lor sensitivity pdf

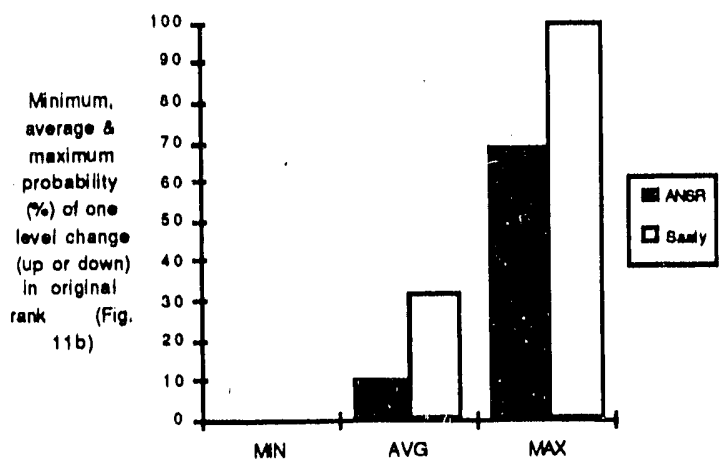

Data base includes original and repeat runs for the LBLOCA and decay heat removal scenarios, and Saaty problem 103 for sensitivity pdf

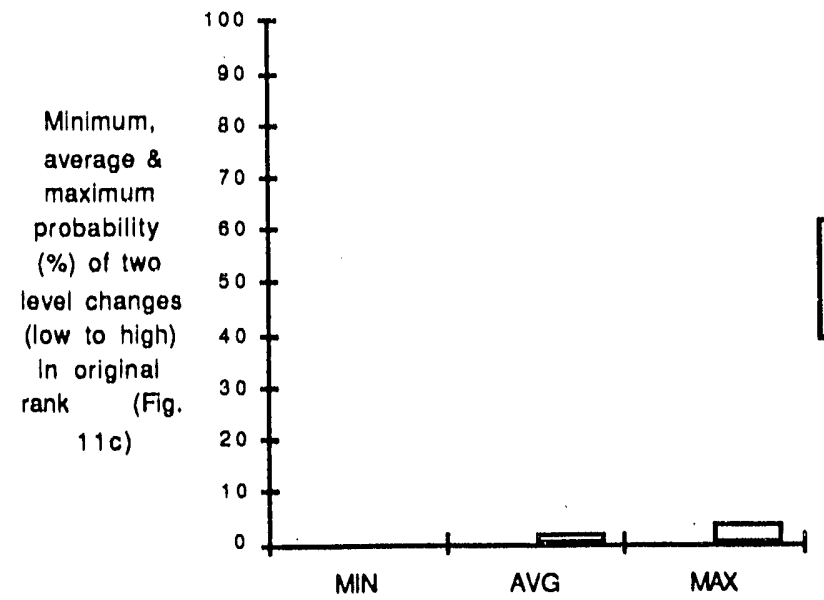

Figure 11. Comparison of ANSR and Saaty problem 103 sensitivity importance levels. 
actually be of high importance (a nonconservative possibility). The data in Tables 10 through 13 show no tendency for high ranked items to decrease to low importance. This may be a fortuitous result; however, it is conservative.

The preceding results reflect the author's previous experience in using the AHP. That is, changes in the pair-wise ranks have an increasing effect on the resulting ordered ranks as the number of elements in a matrix decrease. This is not a surprising effect. Even so, the author concludes the methodology remains robust for fairly small matrices (down to six elements). Figures 10 and 11 show that for a six element matrix the greatest tendency is for the original ranks to have high probabilities of no change in importance levels. On the other hand, the same data strongly indicate that matrices having less than six elements are subject to increasing uncertainty that may become significant. Evaluations of problems of this nature should include specific efforts to quantify the uncertainty in the input (pairwise ranks) and the resulting uncertainty in the output (ordered ranks;. At a minimum, the evaluations would include bounding sensitivity analyses. Statistically based evaluations of uncertainty (such as that done in this report) are still better. 


\section{SUMMARY OF RESULTS AND CONCLUSIONS}

The AHP has been used to help determine the importance of components and phenomena in thermal-hydraulic safety analyses of nuclear reactors. The AHP results are based, in part on expert opinion. Therefore, it is prudent to evaluate the uncertainty of the AHP ranks of importance. A statistically based approach to the subject uncertainty quantification is documented in this report. The work was equally focused toward developing and testing the approach, and to providing results useful to a current program at ORNL.

The new work is based on evaluations of the importance of components and phenomena in the thermal-hydraulic safety analysis of the ANSR, a new facility now in the design phase. The uncertainty during large break loss of coolant, and decay heat removal scenarios is estimated by assigning a probability distribution function (pdf) to the potential error in the initial expert estimates of pair-wise importance between the components. Using a Monte Carlo sampling technique, the error pdfs are propagated through the AHP software analysis to determine a pdf of uncertainty in the system wide importance of each component.

To enhance the generality of the results, study of one other problem having a different number of elements is reported, as are the effects of a larger assumed pdf error in the expert ranks. Validation of the Monte Carlo sample size and repeatability are also documented.

The results and conclusion, of most significance to the objectives of the work, are summarized below in decreasing order of importance.

1. The AHP, when applied as recommended, is a robust methodology with which to determine the ANSR component (and by extension, phenomena) importance.

2. With regard to original application of the AHP to the ANSR, there is zero probability of importance level changes of two (high to low or low to high), regardless of the transient, potential error pdf, or run. In Figures 4 and 5 the zero change and one level change probabilities add to $100 \%$, allowing no probability for a two level change.

3. On the average, the probability for no change in importance level is greater than $87 \%$, with a corresponding one level change of less than $13 \%$ (average values in Figures 4 and 5), regardless of the transient, potential error pdf, or run.

4. On an individual component basis, the $B E$ no change probability can be as low as $40 \%$ (minimum values in Figure 4) and as high as $100 \%$ (maximum values in 
Figure 4). The corresponding values for the sensitivity potential error pdf are $30 \%$ and $100 \%$ (Figure 5).

5. On an individual component basis, the $B E$ one level change probability can be as low as 3\% (minimum values in Figure 4) and as high as 58\% (maximum values in Figure 4). The corresponding values for the sensitivity potential error pdf are 5\% and $69 \%$ (Figure 5).

6. The $B E$ probability of no change is relatively independent of the original rank of the component (low, moderate or high) as illustrated in Figure 4a. The corresponding data for the sensitivity pdf show slightly less independence from the original importance level (Figure $5 a$ ).

7. The probability of one level change is significantly more dependent on the original importance level for both potential error pdfs. In reducing the data the author has noted an increased tendency for importance level switching when the original ordered rank is near the boundary between the levels (i.e., 6-7 and 4-3 in the 1 to 9 scale).

8. The sample size of 10000 used in the Monte Carlo determination of ordered rank uncertainty is judged to be sufficiently large to produce acceptably converged solutions.

a. At 10000 samples the average of the actual pdfs resulting from random selection of the potential error in pair-wise ranks from the specified potential error pdf is essentially identical to the specified pdf (Figures 8a and 9a). The difference in any actual potential error pdfs from the specified pdf is also small as illustrated by the minimum and maximum actual potential error pdfs (Figures $8 a$ and $9 a$ ). The average uncertainty pdfs of the original ordered ranks of the components, normalized to that at 10000 samples, remains essentially equal to one for sample sizes greater than 2000 (Figures $8 \mathrm{~b}$ and $9 \mathrm{~b}$ ). The minimum and maximum normalized uncertainty pdfs decrease with sample size, with the minimum and maximum for sample sizes larger than 9500 being within $\pm 5 \%$ of that at 10000 samples for the $\mathrm{BE}$ pdf, and within $+5 \%,-10 \%$ of that at 10000 samples for the sensitivity pdf. The sufficiency of 10000 samples is further aided by the relative insensitivity of the probability of change in the importance level of the original ordered ranks to the assumed potential error pdf (BE or sensitivity pdfs) as shown in Figures 4 and 5.

b. The data of Figures 6 and 7 show no significant difference between the original and repeat runs. The maximum difference is $1.4 \%$, which occurs in 
the $\mathrm{BE}$ potential error runs at the minimum comparison for zero change, and the maximum comparison for a change of one level in importance.

9. It is concluded the methodology remains robust for fairly small matrices. However, problems involving matrices with less than six elements should include specific efforts to quantify the uncertainty in the input (pair-wise ranks) and the resulting uncertainty in the output (ordered ranks). At a minimum, the evaluations should include bounding sensitivity analyses. Statistically based evaluations of uncertainty (such as that done in this report) are still better. Figures 10 and 11 show that for a six element matrix the greatest tendency is for the original ranks to have high probabilities of no change in importance levels. However, the same data are judged to indicate that matrices having less than six elements are subject to increasing uncertainties that may become significant. 


\section{REFERENCES}

1. Technical Program Group, Quantifying Reactor Safety Margins, NUREG/CR-5249, EG\&G Idaho, Inc. (December 1989).

2. M. A. Bolander, R. G. Hanson, M. G. Ortize and G. E. Wilson, Development of a PIRT for Thermal-Hydraulic Phenomena During a DEGB LOCA in an SRS Production Reactor, EGG-EAST-8618, EG\&G Idaho, Inc. (August 1989).

3. G. E. Wilson, D. C. Wadsworth, and B. G. Miller, Component and Phenomena Based Ranking of Modeling Requirements for the NP-MHTGR Analysis Code Verification and Validation (Final Draft), EGG-NPR-9704, EG\&G Idaho, Inc. (June 1991).

4. Technical Program Group, An Integrated Structure and Scaling Methodology for Severe Accident Technical Issue Resolution (Draft for Comment), NUREG/CR5809, EG\&G Idaho, Inc. (December 1991).

5. J. C. Watkins and L. S. Ghan, AHP Version $5 E$ User's Manual (Draft), EG\&G Idaho, Inc. (March 1990).

6. C. D. West, The Advanced Neutron Source: A New Reactor-Based Facility for Neutron Research, American Nuclear Society Transactions, TANSAO $61 \quad 1-482$ (1990), Vol. 61, 1990 Summer Annual Meeting, Nashville, TN (June 10-14, 1990) pp 375-376.

7. J. D. Hayter, Applications of the Advanced Neutron Source, American Nuclear Society Transactions, TANSAO 61 1-482 (1990), Vol. 61, 1990 Summer Annual Meeting, Nashville, TN (June 10-14, 1990) pp 379.

8. T. L. Saaty, A Scaling Method for Priorities in Hierarchical Structures, J. Mathematical Psychology 15 (1977) pp 234-281.

9. T. L. Saaty, Exploring the Interface Between Hierarchies, Multiple Objectives and Fuzzy Sets, Fuzzy Sets and Systems 1 (1978) pp 57-68.

10 T. L. Saaty, Modeling Unstructured Decision Problems - The Theory of Analytical Hierarchies, Mathematics and Computers in Simulation XX (1978) pp 147-158.

11. T. L. Saaty, Measuring the Fuzziness of Sets, J. Cybernetics 4,4 (1974) pp 53-61.

12. G. A. Miller, The Magical Number Seven, Plus or Minus Two: Some Limits on Our Capacity for Processing Information. Psych. Rev. 43, 2 (1956) pp 81-97.

13. T. L. Saaty, Decision Making for Leaders, University of Pittsburgh, Pittsburgh, PA (1988).

14. T. L. Saaty, Decision Making, The Analytic Hierarchy Process, University of Pittsburgh, Pittsburgh, PA (1988). 


\section{APPENDIX A \\ OVERVIEW OF THE ANALYTIC HIERARCHY PROCESS}

\section{A.1. INTRODUCTION}

As decisions become more and more complex, decision makers are faced with the challenge of sorting through many variables to arrive at a sound decision. The Analytic Hierarchy Process (AHP) is a tool, developed by T, L. Saaty $[A 1, A 2]$, that allows a systematic, logical approach to reducing complex issues into manageable pieces. The decision maker can then sort through the variables and determine to what degree a particular variable should influence the final decision. The power of the AHP as a management tool comes from the fact that it reduces the problem to many pair-wise decisions. Only two items need be compared against one another, a much simpler task than comparing an item to all the others simultaneously. By comparing appropriate pairs in a priority matrix, each item will have been compared with every other item. Matrix algebra can then operate on this priority matrix to rank the items according to their importance toward achieving the goal. The AHP methodology is summarized in Section A.2. More detailed descriptions and numerous applications are available in references $[A 1, A 2, A 3, A 4]$.

\section{A.2. THE ANALYTIC HIERARCHY PROCESS}

As the name suggests, the AHP contains hierarchies or levels. Each level contains items that will be ranked relative to an item in the level above it. By starting at the bottom level, the most fundamental level, the decision maker can rank items with respect to a more general item contained in the next higher level. As the decision maker proceeds through the levels, the items become more general until, finally, the most general item - the goal - is reached. Thus, the decision maker proceeds as if building a pyramid. At the bottom he makes many fundamental decisions. As he proceeds toward the top he makes fewer and fewer decisions but they are more general. Finally the AHP manipulates the decision makers pair-wise decisions to determine how important each of the most fundamental items is with respect to the most general one, the goal. Section A.2.1 describes levels in more detail.

Items in each level are ranked with a tool called a priority matrix. Each entry into a priority matrix compares the relative importance of two items - a pair-wise decision. Each level will contain one or more priority matrices that are filled with pair-wise decisions. Section A.2.2 discusses priority matrices further. 
In the process of building the priority matrices, the decision maker may inadvertently enter decisions that contradict one another. A measurement for the amount of contradiction in a priority matrix is the inconsistency index (IC). ICs from individual priority matrices can be combined to arrive at a measure of contradiction or inconsistency for the entire hlerarchy. The IC is discussed further in section A.2.3.

\section{A.2.1 Levels}

The AHP consists of several levels of decisions, each level representing a different degree of detail in the decision process. One can have has many levels as needed, but for this discussion, assume a three level AHP. The first level always contains the goal to be achieved. The last level contains the items to be prioritized with respect to their effect on achleving the goal, All the levels in between help the decision maker relate the most fundamental items on the bottom level to the goal on the top level. Each level contains items that relate to the more general items in the level above it. The more complex the problem is, the more levels it is likely to have.

For example, if one wants to buy a new car, but is confused by all the cars and options on the market, one might use an AHP with the following levels:

Level 1 Purchasing the car which gives the most satisfaction

Level 2 Items which contribute to satisfaction with the car

Level 3 Specific car models

The decision maker has established a goal (level 1) - to buy a new car he will be satisfied with. The last level (level 3) contains the most fundamental items, the list of car models under consideration. The decision maker could have used a two level hierarchy consisting only of levels one and three. But deciding which car model gives the most satisfaction can be confusing because several items contribute to satisfaction. Therefore, an additional level is established which will help the decision maker relate the most fundamental items to the goal. Figure A1 illustrates the hierarchy. 


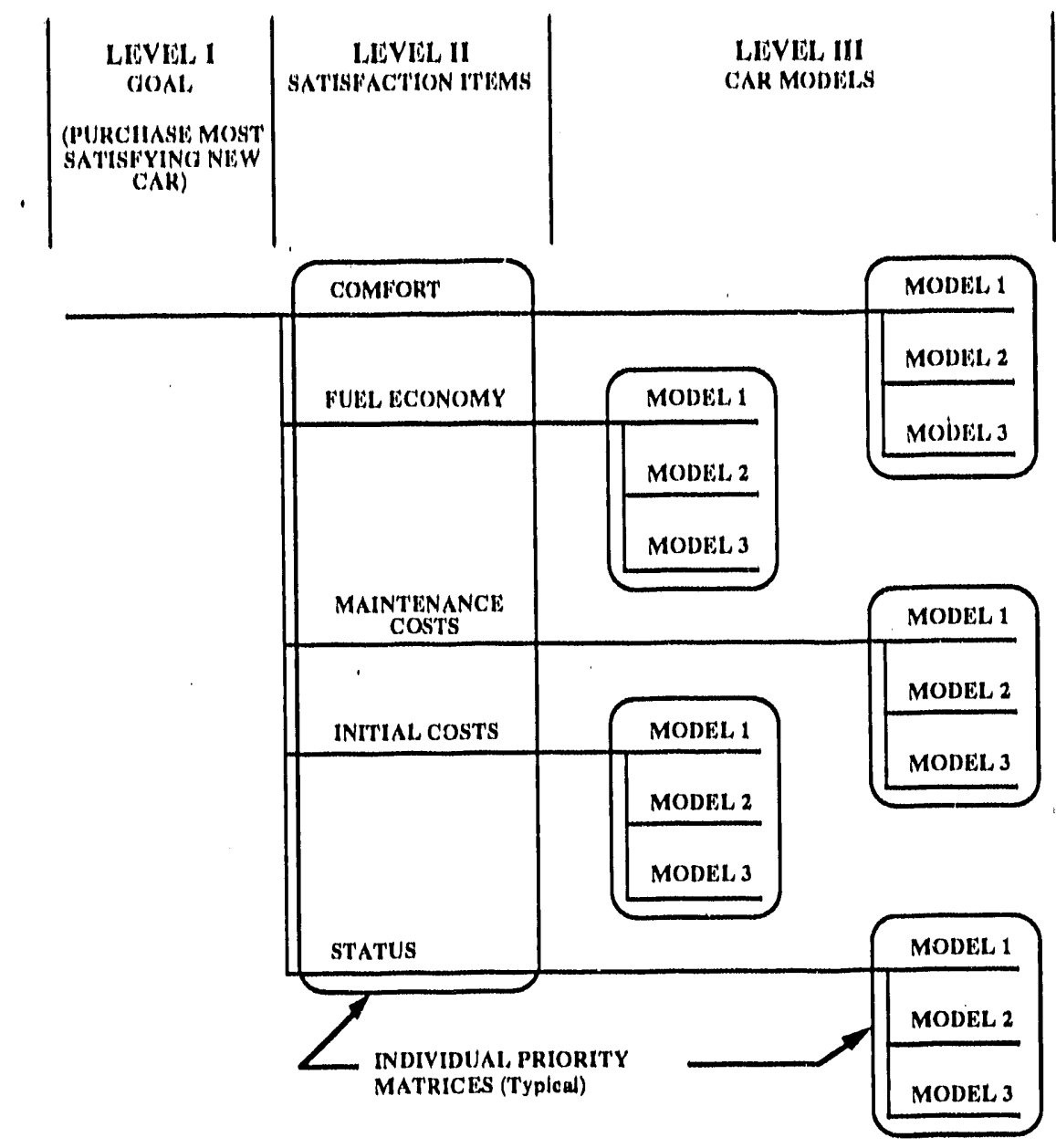

Figure A1. An example hierarchy.

By choosing the items related to satisfaction - say comfort, fuel economy, etc., for the intermediate level (level 2), the decision maker can rank the car models on level 3 with respect to the satisfaction items on level 2. Likewise, he can rank the satisfaction items with respect to the goal, satisfaction. The AHP then uses these rankings in the form of priority matrices to arrive at an overall ranking of the most fundamental items with respect to the goal, i.e. car models ranked with respect to satisfaction. The decision maker would purchase the car model with the highest ranking since it would be the one that best meets his requirements for satisfaction.

\section{A.2.2 Priority Matrices.}

Priority matrices such as the one shown in Figure A2 are key elements in the AHP. It is the priority matrices in which the decision maker enters his pair-wise rankings. Also, the AHP uses the priority matrices to determine the ranking of items 
on each lovel, and the overall hierarchy (the ltoms on the last lovel with respect to the the top lovel), A given set of priority matrioes bridges the levels. The matrix shown in Figure A2 bridges the first and second levels of the hlerarchy because it relates ltems from lovel 2 to lovel 1.

$\begin{array}{lcclll}\text { Sullsfaction } & \text { al } & \text { b. } & \text { e } & \text { d } & \text { e } \\ \text { a. Comfort } & 1 & 1 & 1 / 2 & 1 / 3 & 2 \\ \text { b. Fucl Economy } & 1 & 2 & 3 & 2 \\ \text { c. Malntenance Costs } & & 1 & 1 / 2 & 2 \\ \text { d. Initial Costs } & & & 1 & 3 \\ \text { c. Status } & & & & 1\end{array}$

Figure A2, Example priority matrix.

A description of how to construct priority matrices follows. Each level below lovel 1 will have a set of matrices (level 1 contains no matrix). One matrix will rank ltems in the current level with respect to an item in the level above It. Thus, each level will have as many matrices as there are items in the level above it. Figure A1 Illustrates this. Each box in the figure represents a priority matrix. To construct a priority matrix, the decision maker begins by listing the ltems in the current level along the left of, and at the top of an empty matrix. He enters "1"s on the diagonal (row $a$, column a equals 1 , row $b$, column $b$ equals 1 , etc.). These unit 1 cells indicate that each item is as important as itself. Now, the decision maker is ready to enter pair-wise rankings in the upper right half of the matrix (or, one can enter pair-wise rankings in the lower right half realizing that the two halves of the matrix are reciprocals). Figure $A 2$ is an example of a priority matrix which ranks the items on level 2 with respect to level 1, or satisfaction items with respect to satisfaction. Thus, by evaluating this matrix, the decision maker will know which satisfaction item most contributes to his satisfaction. He doesn't yet know which car to buy; however, he knows what features to look for in a car. In this example, the decision maker has ranked each satisfaction item using a scale from 1 to 3 where 1 iıldicates the left item is equally important to the top ltem when considering the goal. A three indicates that the left item is much more important than the top 1 tem and $1 / 3$ indicates the inverse, the top item is much more important than the left one. The decisions are pair-wise in that the decision maker has made a decision between two items only. For example, comfort is somewhat less important than maintenance cost 
(row a, colunn $c=1 / 2$ ), Each entry into the prlorliy matrix is a pairwwise ranking, l.c. a judgement of how important one ltem is whth respect to the other. Matrix solution schemes whith the program then determine the absolute ranking of the Items within the composite of all ltems. Only the top right corner of the matrix need be fllled in because the lower left portion of the matrix is the inverse of the top right portion, l.c. If Initial cost is much more important than comfort, comfort is much less important than initlal cost. (row a, column d is the inverse of row d, column a). Once the priority matrices are completed, the work for the deciston maker is finlshed. Now the AHP software can operate on the matrices to determine the absolute priorlties.

\section{A.2.3 Consistency.}

It is possible for two declsions to Inadvertently contradict one another in a priority matrix. For example, the decision maker might say that ltem $A$ is more important than $11 \mathrm{~cm} B$, and $11 \mathrm{~cm} B$ is more important than $1 t e m C_{\text {; }}$ but item $C$ is more important than ftem $A$. There is a measurement for the amount of contradiction in a matrix called the inconsistency Index. Inconsistency Indexes from each priority matrix in the hierarchy can be used to determine an overall hicrarchy inconsistency. Generally, if the inconsistency index for a matrix is less than 0.1 , the inconsistency is probably not significant.

The pair-wise ranking scales used as input to the AHP tend to influence the inconsistency. A coarse scale will tend to increase the inconsistency relative to a fline scale; however, the scale selection also depends on other factors as follows. The most coarse scale $\left(\begin{array}{lll}1 & \text { to } & 3\end{array}\right)$ is the easiest to use in the pair-wise ranking. That is, it is easy to decide that two parameters are of equal importance (1), or that one is somewhat more important (2) or significantly more important (3). It is more difficult to rank using a scale of 1 to 9. Experience indicates that what is usually done is to establish 1 as equally important, 5 as somewhat more important, 9 as significantly more important, and then use the in-between numbers to resolve differences in the opinions of the personnel performing the ranking. Based on considerable experience the normal recommendation is to use a scale of 1 to 5 . This scale usually. provides the best compromise relative to ease of use and influence on the inconsistency of the resulting product.

It should be noted the preceding discussion applies only to the pair-wise ranking scales which are input to the AHP software. The relative ranking performed by the AHP software is output in a scale which is nermalized to the total (i.e., zero to one). 
This seale is further converted to a relillive soule of 1 to 9 by assigning 1 to the lowest normalized value, 9 to the highest normalized value, and then linearly interpolating the remalning normalized values. It has been found the 1 to 9 relative seale is generally more convenient in revlowing the relative importance of the ltems at each hierarchloal lovel.

\section{A.2.4 Conceptional Illustration of AHP Application to Nuclear Reactor}

\section{Accident Analysis}

Figure A3 lllustrates, in conceptional form, a typical application of the AHP to determine the importance of phenomena in nuclear reactor safety analysis.

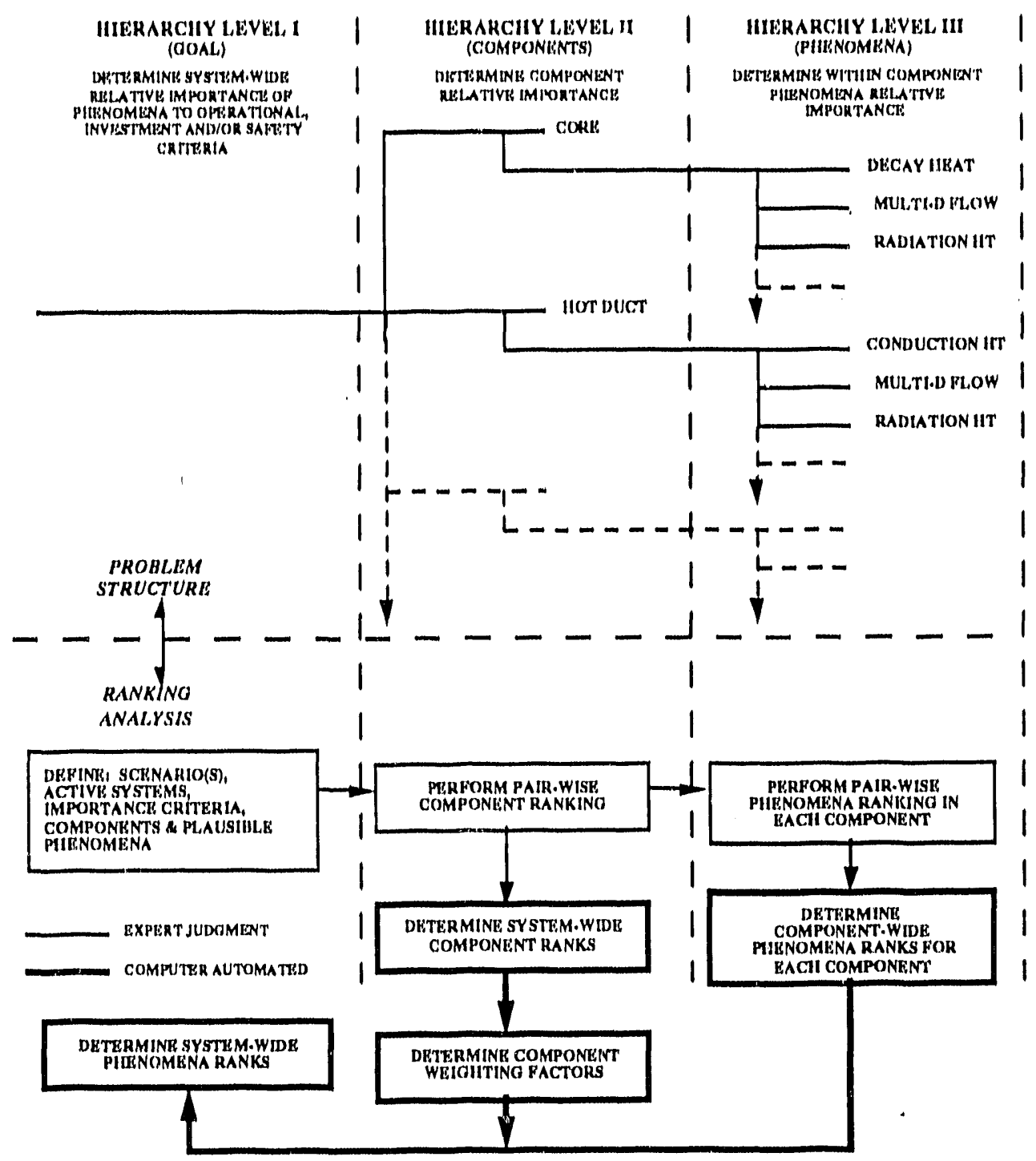

Figure A3. Illustration of the process to determine the relative importance of phenomena to operational, investment and/or safety criteria. 


\section{REFERENCES}

A1. T. L. Saaty, Decision Making for Leaders, University of Pittsburgh, Plttsburgh, PA (1988),

A2. T. L. Saaty, Decision Making. The Analytic Hierarchy Process, University of Pittsburgh, Pittsburgh, PA (1988).

A3, B, L. Golden et al. (Editors), The Analytic Hierarchy Process, Applications and Studies Springer-Verlag, New York, NY (1989).

A4. M. J. Liberatore, A Decision Support System Linking Research and Development Project Selection with Business Strategy, Project Management Journal, Vol. XIX, No, 5 (November 1988) p. 14.

A5. J. C. Watkins and L. S. Ghan, AHP Version 5E, Draft User's Manual, EG\&G Idaho, Inc. (1990). 


\section{APPENDIX B \\ VALIDATION OF SOLUTION TECHNIQUE AND SOFTWARE}

\section{B.1. AHP SOLUTION TECHNIQUES}

Saaty has described two solution methods $[\mathrm{B} 1, \mathrm{~B} 2]$ for the matrix algebra associated with calculating ordered ranks of Importance from the pair-wise ranks. The first is itcrative and more accurate. The itcration is associated in insuring the optimum solution is achleved even though there may be some inconsistency in the palr-wise ranks. Dimenna based his work[B3] on the iterative approach, it being different from Saaty in the relaxation of the need for identical matrices in each level of the hierarchy through a different normalization scheme. The Dimenna approach is the one programmed in the AHP software used by the TRG to obtain their BE results.

Saaty's second method is an approximation of the iterative approach, and has the advantage of a single pass treatment (i.e., a reduced number of algebralc operations). All three methods give identical results for matrices which are perfectly consistent. In the current work the reduced algebraic operations of the approximate method had a significant attraction because of the several millions of operations necessary for the statistical analysis, and because it is significantly less difficult to program.

To insure the approximate method was adequate for the purpose of this work, certain studies were conducted to validate the method and the resulting software. The results from these siudies are summarized in Tables B1 through B3. Table B1 shows comparisons of the three solution techniques for a Saaty problem (referred to here as 103) originally used to validate the Dimenna method[B3]. Tables B2 and B3 show comparisons of the approximate and Dimenna solutions for the ANSR LBLOCA and Decay Heat scenarios, respectively. In all three tables, the approximate method is shown as solved by hand (actually by a PC spread sheet), and by the AHP-SA soltware, which is the author's implementation of the AHP on a Macintosh IIcx PC including the statistical analysis steps.

From the results in these tables we conclude the approximate solution method is adequate for the objective and that the AHP-SA software is correctly implemented. 
Table B1. Comparison of AHP solution formulations for Saaty problem 103

\begin{tabular}{|c|c|c|c|c|c|c|}
\hline \multicolumn{7}{|c|}{ INPUT PAIR-WISE RANKS AND SUM OF COLUMES } \\
\hline & 1 & 2 & 3 & 4 & 5 & 6 \\
\hline 1 . Sottness & 1.0000 & 0.2500 & 0.2000 & 0.2500 & 5.0000 & 0.1667 \\
\hline 2. Absorptiveness & 4.0000 & 1.0000 & 0.3333 & 3.0000 & 6.0000 & 0.5000 \\
\hline 3. Price & 5.0000 & 3.0000 & 1.0000 & 4.0000 & 7.0000 & 3.0000 \\
\hline 4. Size & 4.0000 & 0.3333 & 0.2500 & 1.0000 & 5.0000 & 0.2000 \\
\hline 5. Design & 0.2000 & 0.1667 & 0.1429 & 0.2000 & 1.0000 & 0.1429 \\
\hline 6. Integrity & 6.0000 & 2.0000 & 0.3333 & 5.0000 & 7.0000 & 1.0000 \\
\hline Colume Sum & 20.2000 & 6.7500 & 2.2595 & 13.4500 & 1.0000 & 5.0095 \\
\hline
\end{tabular}

\begin{tabular}{|c|c|c|c|c|c|c|c|}
\hline \multicolumn{7}{|c|}{ (PAIR-WISE RANK) DIVIDED BY (COLUME SUM) FOLLOWED BY (ROW SUM /N) } & \multirow{2}{*}{$\begin{array}{r}\text { Row Sum) } / N \\
0.0647\end{array}$} \\
\hline 1. Softness & 0.0495 & 0.0370 & 0.0885 & 0.0186 & 0.1613 & 0.0333 & \\
\hline 2. Absorptiveness & 0.1980 & 0.1481 & 0.1475 & 0.2230 & 0.1935 & 0.0998 & 0.1683 \\
\hline 3. Price & 0.2475 & 0.4444 & 0.4426 & 0.2974 & 0.2258 & 0.5989 & 0.3761 \\
\hline $4 . \operatorname{Siz\theta }$ & 0.1980 & 0.0494 & 0.1106 & 0.0743 & 0.1613 & 0.0399 & 0.1056 \\
\hline 5. Design & 0.0099 & 0.0247 & 0.0632 & 0.0149 & & 0.0285 & 0.0289 \\
\hline 6. Integrity & 0.2970 & 0.2963 & 0.1475 & 0.3717 & 0.2258 & 0.1996 & 0.2563 \\
\hline
\end{tabular}

\begin{tabular}{|c|c|c|c|c|c|c|c|c|}
\hline \multicolumn{9}{|c|}{ COMPARISON OF SAATY(Aproximate), DIMENNA AND SAATY!!tertive) AHP SOLUTIONS } \\
\hline & $\begin{array}{l}\text { Saaty(AP) } \\
\text { Nor. Rank }\end{array}$ & $\begin{array}{l}\text { Dimenna } \\
\text { Nor. Rank }\end{array}$ & $\begin{array}{l}\text { Paaty }(I T) \\
\text { Nor. Rank }\end{array}$ & $\begin{array}{l}\text { Saaty }(A \bar{P}) \\
\text { Rel. Rank }\end{array}$ & $\begin{array}{l}\text { Dimenna } \\
\text { Rel. Rank }\end{array}$ & $\begin{array}{l}\text { Saaty (IT) } \\
\text { Rel. Rank }\end{array}$ & $\begin{array}{l}\text { AHP.SA } \\
\text { Nor. Rank }\end{array}$ & $\begin{array}{l}\text { AHP.SA } \\
\text { Rel. Rank }\end{array}$ \\
\hline Price & 0.3761 & 1.0000 & 0.3837 & 9 & 9 & 9 & 0.3761 & 9 \\
\hline Integrity & 0.2563 & 0.6887 & 0.2643 & 6 & 6 & 6 & 0.2563 & 6 \\
\hline Absorptiveness & 0.1683 & 0.0700 & 0.1679 & 4 & 4 & 4 & 0.1683 & 4 \\
\hline Size & 0.1056 & 0.4376 & 0.1002 & 3 & 3 & 3 & 0.1056 & 3 \\
\hline Softness & 0.0647 & 0.2612 & 0.0570 & 2 & 2 & 2 & 0.0647 & 2 \\
\hline Desian & 0.0289 & 0,1484 & 0.0269 & 1 & 1 & 1 & 0.0289 & 1 \\
\hline
\end{tabular}

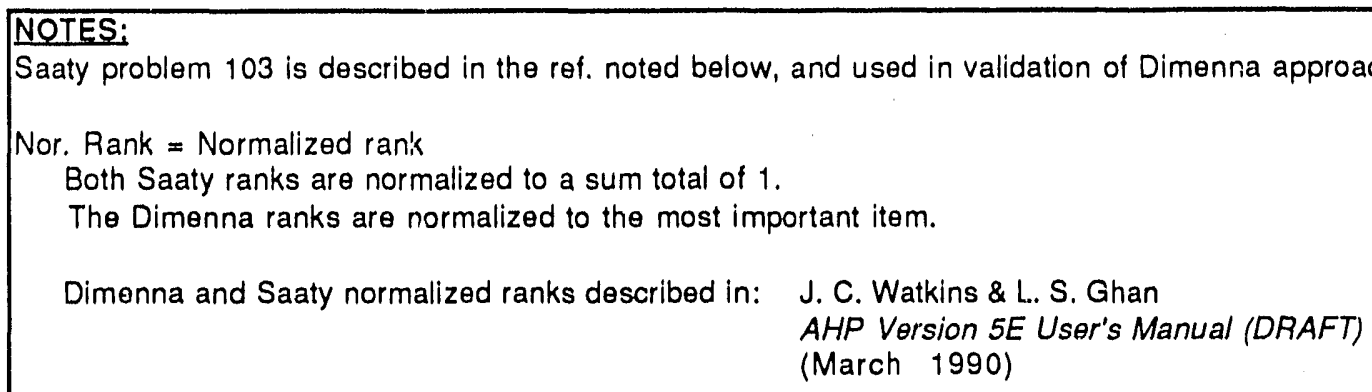

Rel. Rank $=$ Relative rank on a scale of 1 to 9

All three relative ranks are derived from their respective normalized ranks 

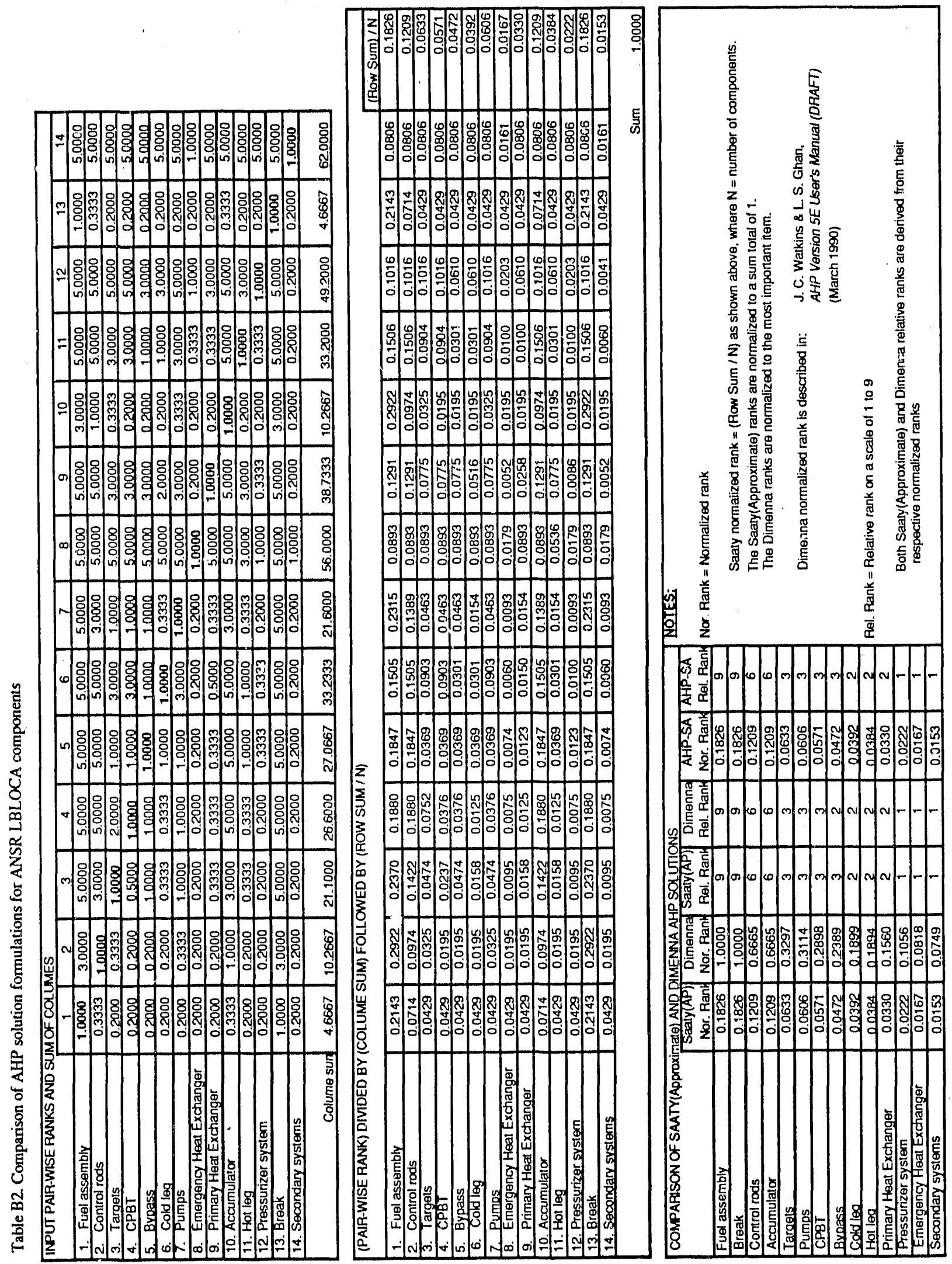

\section{B-3}




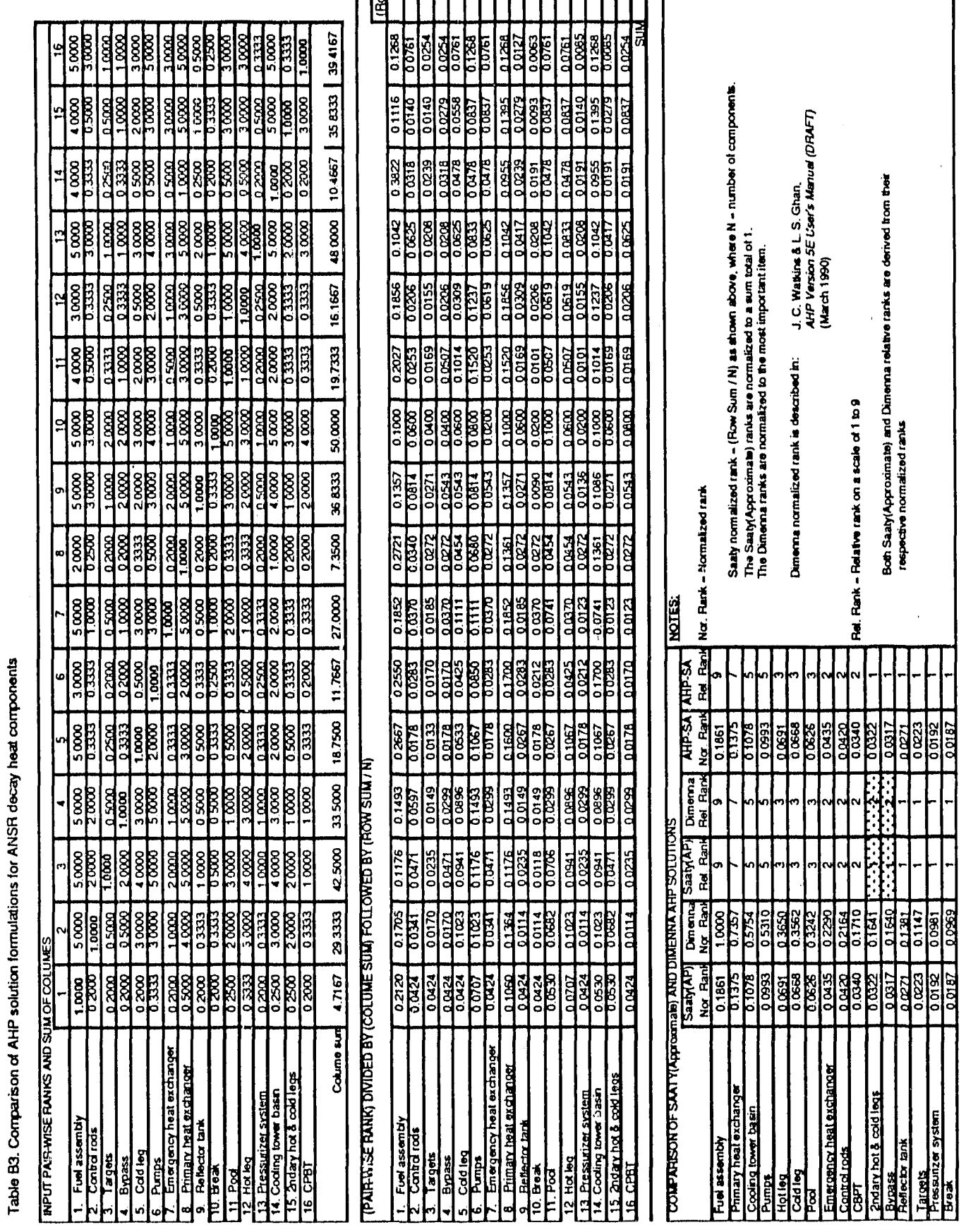

B- 4 


\section{B.2. CONVERGENCE OF IMPORTANCE RANKS WITH INCREASING MONTE CARLO SAMPLES}

The study reported in the mainbody of this report was initiated by examination of the effects of sample size on the random selection scheme used to implement a specified pdf for the potential error in the original experts pair-wise ranking. The actual pdf resulting from a random selection from the specified pdfs shown in Figures 2 and 3 of the mainbody of the report were generated as a function of increasing sample size, from 500 to 20000 samples. These results are plotted in Figures B1 through B4 for sample sets of 2000 and above. Figures B1 and B3 compare the implemented pdf with the specified pdf at 10000 samples for the BE and sensitivity specified pdfs, respectively. Figures B2 and B4 shown implemented pdfs (normalized to that at 10000 samples) as a function of sample size for the BE and sensitivity specified pds, respectively.

Figures B1 and B3 show the implemented pdfs have essentially converged at 10000 samples, to that specified. The convergence is best for the sensitivity pdf. The convergence in the $\mathrm{BE}$ pdf is increasingly less exact as the potential error increases (either up or down). This is not a surprising result because in the BE pdf the probability of selecting a specific error decreases at a high rate as the error size increases from zero. The sensitivity pdf experiences the same trend; however, because the probability of selecting the larger errors is larger, the implemented pdfs converge faster with increasing sample size.

Figures B2 and B4 show that for both specified pdfs, the implemented pdfs for changes of \pm 2 and smaller converge very quickly to the specified pdf (i.e., before 10000 samples). This is also true for the \pm 3 change in the sensitivity pdf. However, the results in Figure B2 indicate that the BE implemented pdf for a \pm 3 change has not necessarily stabilized at 10000 samples. In retrospect, the purity of the statistical results reported in the mainbody would have been strengthened by using larger sample sizes. However, it is judged the results in the mainbody remain valid based on the following rationale:

a) The -3 and +3 nonconvergence shown in Figure $B 1$ is sufficiently small $(+30 \%$ and $-20 \%$, respectively), and tends to be offsetting on the average (i.e., the higher probability of a -3 change is partially compensated by the lower probability of the +3 change), 
b) The effects of the possible nonconverged solutions are believed to be totally or mostly captured in the repeat runs, and these effects are small (mainbody Figures 6 and 7), and

c) The results summarized in Figures 4 and 5 in the mainbody of the report show the uncertainty in the original ordered ranks is not a strong function of the specified potential error pdf (one with a well converged solution). 
Figure B1. Convergence of implemented pdf at 10000 samples to specifled BE pdf.

Speoifled BE pdf Implemented pdf

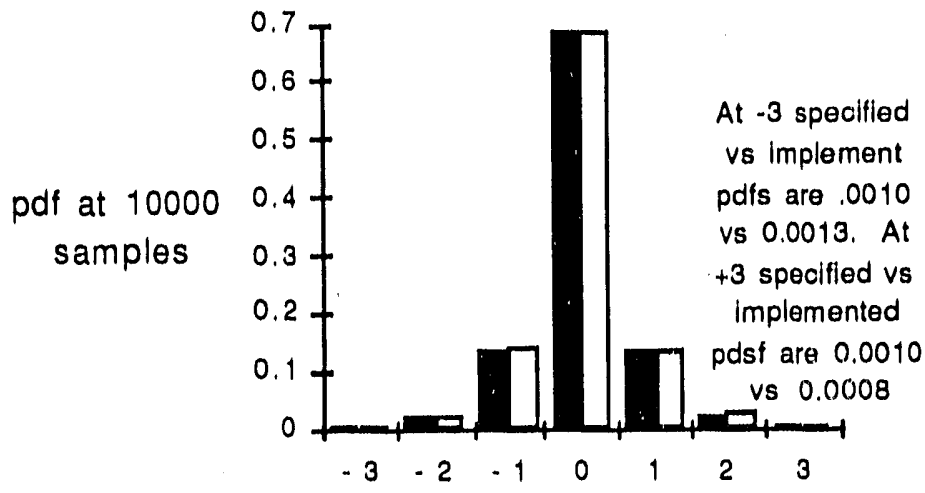

Potentlal error in expert pair-wise ranks

Figure B2. Convergence of pdf with increasing sample size for check out of implemented versus specified BE potential error pdf.

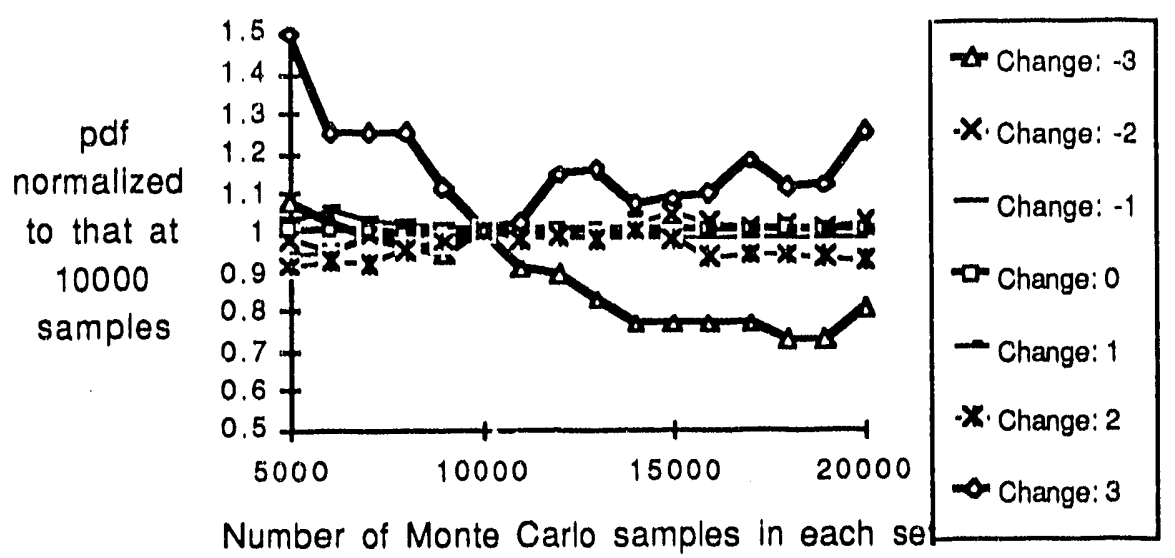

B-7 
Figure B3. Convergence of implemented pdf at 10000 samples to specified sensitivity pdf.

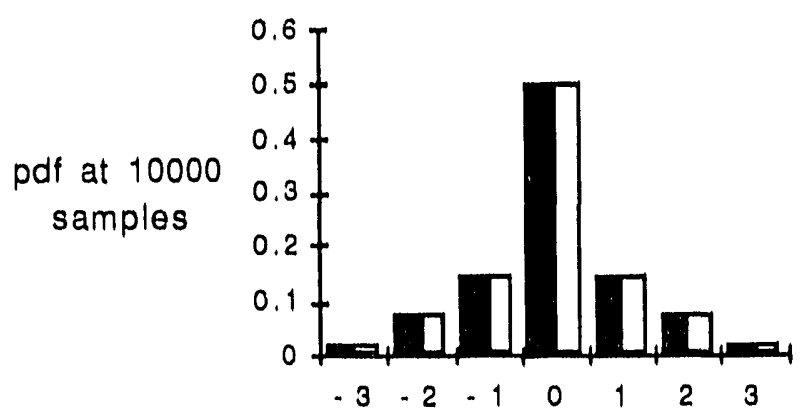

Potentlal error in expert palr-wise ranks

Figure B4. Convergence of pdf with increasing sample size for check out of implemented versus specifled sensitivity potential error pdf:

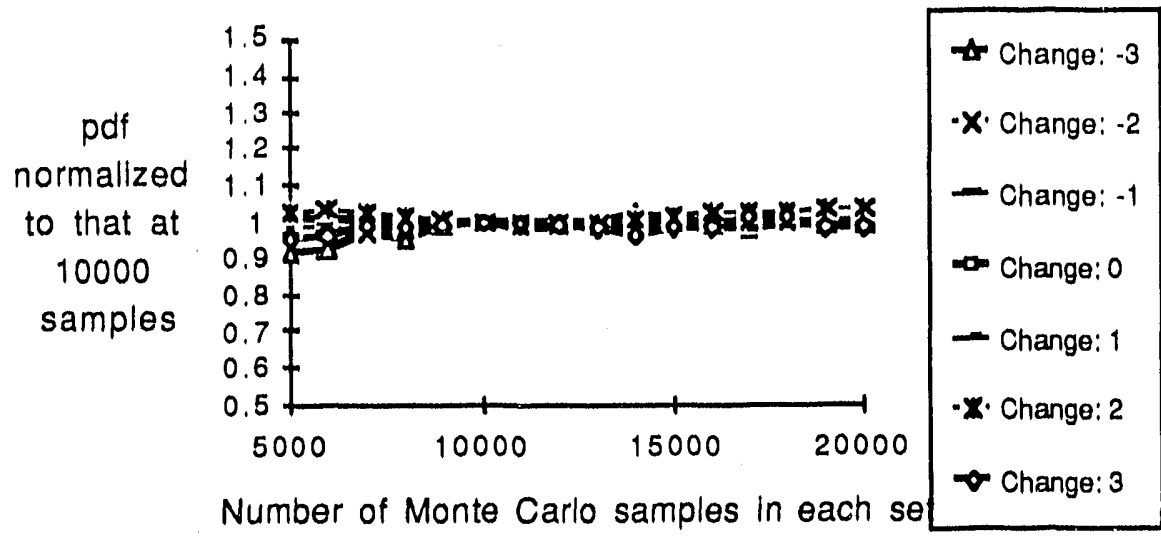




\section{REFERENCES}

B1. T. L. Saaty, Decision Making for Leaders, University of Pittsburgh, Pittsburgh, PA (1988),

B2. T. L. Saaty, Decision Making. The Analytic Hlerarchy Process, University of Pittsburgh, Pittsburgh, PA (1988).

B3. J. C. Watkins and L. S. Ghan, AHP Version SE, Draft User's Manual, EG\&G Idaho, Inc. (1990). 

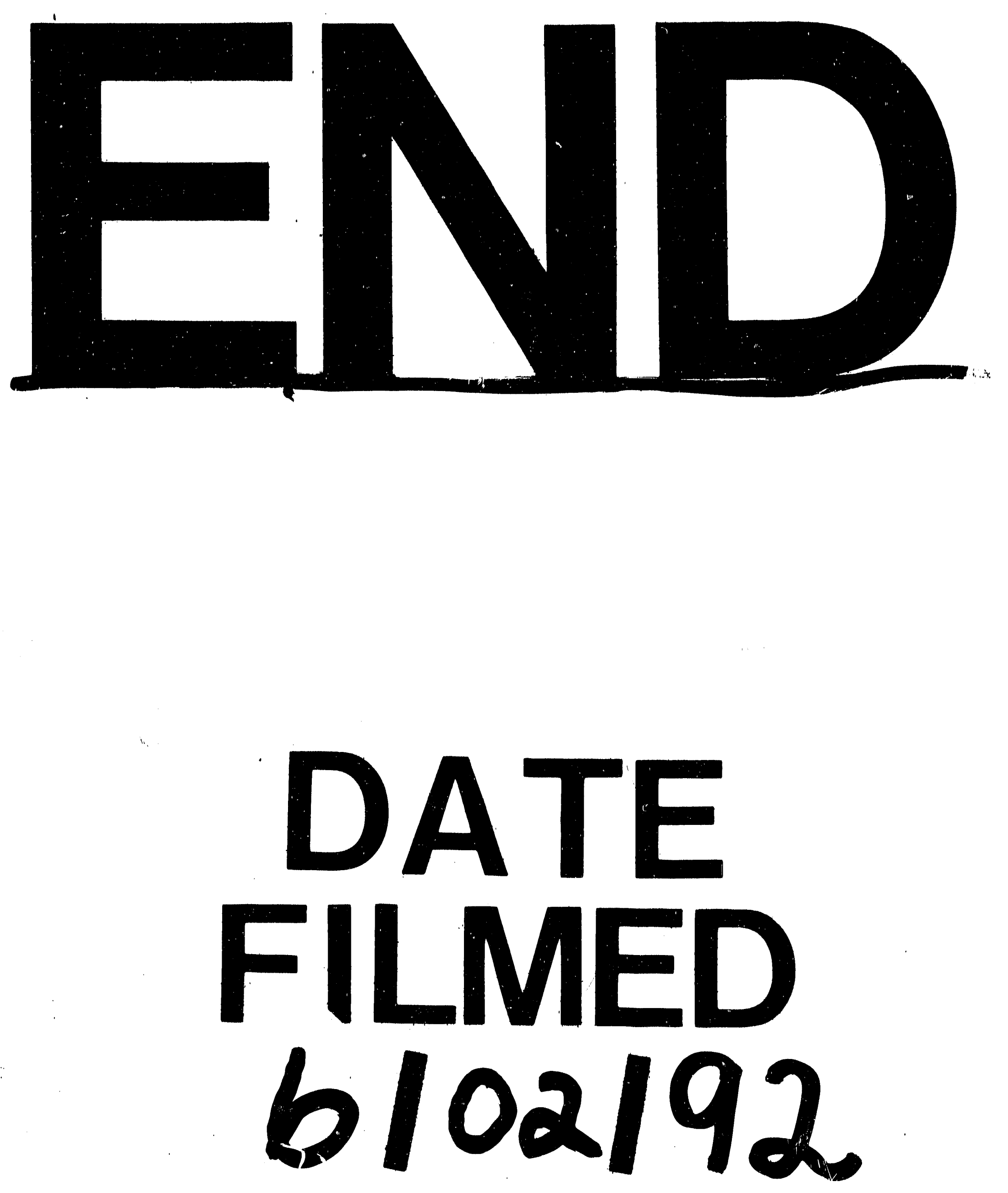
